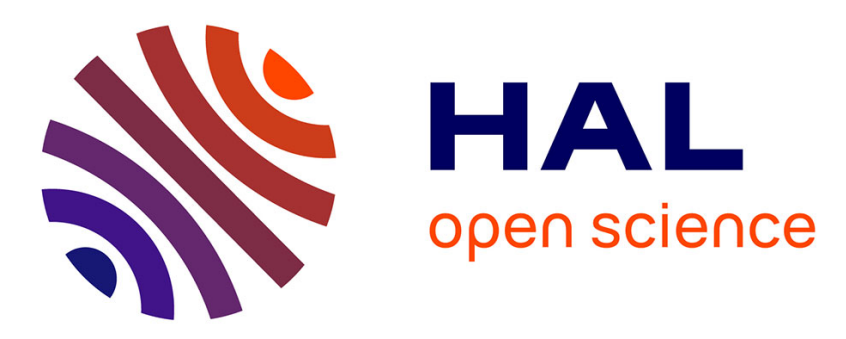

\title{
Optimal Fiscal Devaluation
}

François Langot, Lise Patureau, Thepthida Sopraseuth

\section{To cite this version:}

François Langot, Lise Patureau, Thepthida Sopraseuth. Optimal Fiscal Devaluation. 2012. hal00989916

\section{HAL Id: hal-00989916 https://hal.univ-lille.fr/hal-00989916}

Preprint submitted on 12 May 2014

HAL is a multi-disciplinary open access archive for the deposit and dissemination of scientific research documents, whether they are published or not. The documents may come from teaching and research institutions in France or abroad, or from public or private research centers.
L'archive ouverte pluridisciplinaire HAL, est destinée au dépôt et à la diffusion de documents scientifiques de niveau recherche, publiés ou non, émanant des établissements d'enseignement et de recherche français ou étrangers, des laboratoires publics ou privés. 


\section{Document de travail}

\section{- $[2012-13]$ \\ “Optimal Fiscal Devaluation”}

François Langot, Lise Patureau, Thepthida Sopraseuth

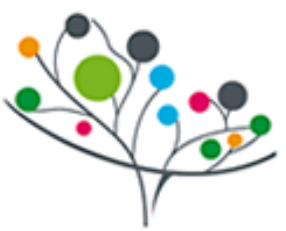

Université Lille Nord de France

Pole de Recherche

et dEnselgnement Superieur 


\section{Optimal Fiscal Devaluation}

François Langot, Lise Patureau and Thepthida Sopraseuth

\section{François Langot}

Paris School of Economics, Université du Mans (GAINS-TEPP) \& Cepremap. flangot@univ-lemans.fr

\section{Lise Patureau}

PRES Université Lille Nord de France, Université Lille 1, Laboratoire EQUIPPE EA 4018, Villeneuve d'Ascq, France.

Lise.Patureau@univ-lille1.fr

\section{Thepthida Sopraseuth}

Université du Mans (GAINS-TEPP) \& Cepremap.

thepthida.sopraseuth@univ-lemans.fr 


\title{
Optimal Fiscal Devaluation
}

\author{
François Langot ${ }^{* \dagger} \quad$ Lise Patureau Thepthida Sopraseuth $^{\ddagger}$
}

April 2012

\begin{abstract}
We study fiscal devaluation in a small-open economy with labor market search frictions. Our analysis shows the key role of both dimensions in shaping the optimal tax scheme. By reducing labor market distortions, the tax reform is welfare-improving. Yet, as it makes imports more expensive, fiscal devaluation lowers the agents' purchasing power, which is welfare-reducing. These contrasting effects give rise to an optimal tax scheme. Besides, transition matters. If the economy is better off in the long run, the required transitional saving effort increases the cost of the reform, thereby calling for a moderate magnitude of fiscal devaluation.
\end{abstract}

Keywords: fiscal devaluation, consumption tax, payroll tax, labor market search, small open economy, Dynamic General Equilibrium model

JEL classification: E27, E62, H21, J38

${ }^{*}$ Paris School of Economics, Université du Mans (GAINS-TEPP) \& Cepremap. Email:flangot@univ-lemans.fr

${ }^{\dagger}$ The paper has been initiated as a part of a research program conducted by the Cepremap, which we also thank for financial support. The paper has also benefited from the fruitful comments made at the T2M conference (Montreal, 2011), the EALE congress (Cyprus, 2011) and the French Labor Market workshop (Aussois, 2011), as well as at the seminar of the University of Lille 1. Omissions and mistakes are ours.

${ }^{\ddagger}$ EQUIPPE (Université de Lille 1) \& CES. Email: lise.patureau@univ-lille1.fr

§Université du Mans (GAINS-TEPP) \& Cepremap. Email: thepthida.sopraseuth@univ-lemans.fr 


\section{Introduction}

The current euro zone crisis has spurred a renewed interest in fiscal devaluation as a tool to restore growth, correct external balances and boost employment. Fiscal devaluation consists in reforming the tax scheme by shifting the tax burden from the employers' social contribution towards consumption taxes. Such a reform is expected to mimic the effects of exchange rate devaluations, as the labor tax cut would reduce labor costs, thus producer prices, while the consumption tax increase would boost import prices without bearing on exports, whose relative price would fall. In this respect, the budget-neutral fiscal devaluation can make exports cheaper and imports more expensive, thereby boosting the demand for domestic goods and reducing external imbalances. The second leading argument behind fiscal devaluation relates to labor market performances. By lowering labor cost, this policy could favor labor demand and employment while ensuring the financial sustainability of social welfare. The need for a reduced labor cost would be all the more necessary in the case of European labor markets, as they exhibit a substantial degree of rigidity notably attributable to stringent labor market institutions and labor taxation (Blanchard \& Wolfers (2000)). Prescott (2004) indeed studies the role of taxes in accounting for differences in labor market outcomes between European countries and the US. He finds that fiscal distortions on the labor supply explain most of the differences at points of time and the large change in relative (to US) labor market outcomes over time. ${ }^{1}$ According to Lucas (2003), the utility consequences for France, of adopting American tax rates on labor and consumption "would be equivalent to a 20 percent increase in consumption with no increase in work effort". This provides a supplementary argument in favor of implementing fiscal devaluation in European countries.

Some countries, such as Denmark (in 1987), Germany (in 2007) or France (2012) have already implemented such a tax reform. If some economists have recently called attention on this reform, ${ }^{2}$ little is yet known about the magnitude of the potential gains from such fiscal devaluation, notably in terms of employment and welfare. This is the focus of the paper.

We propose a small-open-economy model with labor market search and matching frictions to assess the potential gains from fiscal devaluation. In this framework, we provide a careful evaluation of the positive and normative implications of fiscal devaluation. ${ }^{3}$ Our main contribution to the literature lies in stressing the role of labor market frictions in assessing the effectiveness of fiscal

\footnotetext{
${ }^{1}$ On this line of research, Rogerson (2006) or Ohanian et al. (2008) suggest that a theory providing a link between the aggregate hours and taxes seems to be sufficient to explain why Europeans work less than Americans. The aggregate hours worked in Continental European countries are roughly one third less than in the US.

${ }^{2}$ Cavallo and Cottani on VoxEU (http://www.voxeu.org/index.php?q=node/4666); and IMF (2011).

${ }^{3}$ Fiscal devaluation refers here to a cut in the employers' social security contribution associated with a rise in consumption tax. We do not consider changes in tariff and export subsidy since we want to focus on labor market frictions. Furthermore, we will not consider value-added taxation because, as pointed out by Farhi et al. (2011), consumption tax and value-added tax are equivalent when prices are flexible (complete pass-through of tax changes), which is the case in our model.
} 
devaluation. The related papers rather focus on product market imperfections and nominal rigidities (Farhi et al. (2011), Adao et al. (2009)). We discard this issue, which mostly relates to short-run adjustments, by assuming that prices and wages are flexible. However, labor market frictions and wage negotiation (search and matching models à la Diamond (1982), Mortensen (1982) and Pissarides (1985)) lead to an inefficient unemployment level, thereby leaving scope for the fiscal policy. Search frictions as an explanation of the "labor wedge" are indeed evoked by Shimer (2009) as a promising approach. They accordingly stand at the heart of our investigation. Our originality also consists in pointing out the key role of the open-economy dimension, next to that of labor market frictions, in shaping the optimal tax scheme. In an intertemporal framework, we thus evaluate the long-run as well as the short-run effects of fiscal devaluation, relying on both analytical results and quantitative simulations. In this respect, our paper contributes to a better understanding of the overall implications of the tax reform.

The paper's contribution can be summarized in three main results. First, we show the analytical conditions under which the tax reform can be welfare-improving in the long run. The first key condition relates to tax base comparison. It should indeed be the case that the consumption tax base is larger than the payroll tax base. Under this condition, we show that fiscal devaluation is always welfare-enhancing in a closed-walrasian setting, as it reduces the overall tax burden. Adding the open-economy dimension modifies the picture. By making imports more expensive, fiscal devaluation induces a relative price effect which is welfare-detrimental. These contrasting effects give rise to an optimal tax scheme. Second, we provide a careful quantitative assessment of the optimal tax reform. Using France as benchmark economy, we thus show that there is room for fiscal devaluation, as our model predicts an optimal payroll tax rate of $24 \%$ (versus $34 \%$ in the benchmark (current) situation). Third, we put into evidence some key determinants that condition the effectiveness of the tax reform. Precisely, we show the contrasting roles of labor market frictions and the open-economy dimension, in shaping the optimal tax scheme. On the one hand, stringent labor market institutions (ie, a generous unemployment benefit system) call for a large magnitude of the labor tax cut. On the other hand, this is all the less welcome as the agents suffer from a strong relative price effect, which crucially depends on the trade balance adjustments. In particular, the less domestic and foreign varieties are substitutable, the higher the increase in import prices and in the home CPI, thereby calling for an "anti-fiscal" devaluation. We also show that transition matters in designing the optimal tax reform. If, by reducing overall tax distortions, fiscal devaluation ensures large welfare gains in the long run, this can only be achieved if agents agree to endure some losses in the short run, associated to the necessary saving effort in the accumulation of assets (capital and employment) that has to be made. Taking into account the transitional costs of the tax reform thereby mitigates the magnitude of the labor tax-cut, hence of the overall fiscal distortions.

The paper is organized as follows. We present the small-open-economy search model in Section 
2. To deeply understand the effects of fiscal devaluation, we adopt a progressive approach. In Section 3, we abstract from labor market frictions, to consider a frictionless open economy. This allows us to put emphasis on the key role of the open-economy dimension in shaping the optimal tax scheme. We then ask for the optimal tax scheme when labor market frictions are embodied in the model. This is made in Section 4. In particular, we propose a quantitative assessment of the optimal tax reform in France. We also provide a sensitivity analysis to the labor market institutions and the trade elasticity, as both dimensions are shown to play a key role in the optimal tax design. Section 5 concludes.

\section{The open-economy search model}

\subsection{Labor market flows}

Employment is predetermined at each time and changes only gradually as workers separate from jobs, at the exogenous rate $s(0<s<1)$, or unemployed agents find jobs. Let $N_{t}, V_{t}$ and $M_{t}$, respectively be the number of workers, the total number of new jobs made available by firms, and the number of hirings per period, determined by a constant returns to scale matching function (Pissarides (1990)), then employment evolves according to:

$$
N_{t+1}=(1-s) N_{t}+M_{t} \quad \text { with } M_{t}=\chi V_{t}^{\psi}\left[e_{t}\left(1-N_{t}\right)\right]^{1-\psi}, \quad 0<\psi<1
$$

with $\psi$ the weight of vacant jobs in the match process and $e_{t}$ the average search effort of all workers. $e_{t}\left(1-N_{t}\right)$ thus captures the total number of search effort by the unemployed in the economy. $\chi>0$ is a scale parameter measuring the efficiency of the matching function. The labor force is constant and normalized to one, then $1-N_{t}$ is also the unemployment rate.

Let $e_{i}$ be the search effort of an individual worker $i$. Worker $i$ 's probability of finding a job is equal to $\widetilde{p}_{i}=\frac{e_{i}}{e} \frac{M(V, N)}{(1-N)}$. Since all workers are identical, the symmetric equilibrium leads to $e_{i}=e \forall i$, which implies $\widetilde{p}_{i}=\widetilde{p}$, with $\widetilde{p}$ the aggregate job finding rate. Defining labor market tightness $\theta$ as:

$$
\theta_{t}=\frac{V_{t}}{e_{t}\left(1-N_{t}\right)}
$$

the average job finding rate can be rewritten as: $\widetilde{p}_{t}=e_{t} \chi \theta_{t}^{\psi}=e_{t} p_{t}$, with $p_{t} \equiv \frac{M\left(V_{t}, N_{t}\right)}{e_{t}\left(1-N_{t}\right)}$. Alternatively, we have $\theta_{t}=p_{t} / q_{t}$. At the level of the firm, the vacancy filling rate $q_{t}$ is $\frac{M}{V}$ or $q_{t}=\chi \theta_{t}^{\psi-1}$. The job finding rate $\widetilde{p}_{t}$ (the probability of filling a vacant job $q_{t}$ ) is an increasing (decreasing) function of labor market tightness.

\subsection{Households}

The economy is populated by a large number of identical households whose measure is normalized to one. Each household consists of a continuum of infinitely-lived agents. The household's 
program consists in an intertemporal arbitrage (consumption-savings) and intratemporal arbitrages (allocation across varieties).

The intertemporal program The consumption smoothing choice interacts with the labor market behavior. Each period, an agent can engage in only one of three activities: working, searching for a job or enjoying leisure. Employed agents $(N)$ work $h$ hours, while unemployed $(1-N)$ spend their time searching a job. Unemployed agents are randomly matched with job vacancies. Individual idiosyncratic risks faced by each agent in his job match are smoothed by using employment lotteries. Hence, the representative household's preferences are:

$$
\sum_{t=0}^{\infty} \beta^{t}\left[N_{t} U\left(C_{t}^{n}, h_{t}\right)+\left(1-N_{t}\right) U\left(C_{t}^{u}, e_{t}\right)\right]
$$

with $0<\beta<1$ the discount factor. The time period is normalized to 1 . $C_{t}^{n}$ and $C_{t}^{u}$ stand for the consumption of employed and unemployed agents respectively, while $h_{t}$ denotes worked hours and $e_{t}$ search effort of the unemployed. We assume separability between consumption and leisure, ie for employed and unemployed workers respectively:

$$
\begin{array}{lrr}
U\left(C_{t}^{n}, h_{t}\right)=\log C_{t}^{n}+\Gamma_{t}^{n} & \text { with } & \Gamma_{t}^{n}=-\sigma_{n} \frac{h_{t}^{1+\eta_{L}}}{1+\eta_{L}} \\
U\left(C_{t}^{u}, e_{t}\right)=\log C_{t}^{u}+\Gamma_{t}^{u} & \text { with } & \Gamma_{t}^{u}=-\sigma_{u} \frac{e_{t}^{1+\eta_{L}}}{1+\eta_{L}}
\end{array}
$$

with $\eta_{L}>0, \sigma_{n}>0$ and $\sigma_{u}>0$. For the representative household, employment lotteries evolve according to:

$$
N_{t+1}=(1-s) N_{t}+e_{t} p_{t}\left(1-N_{t}\right)
$$

The household's budget constraint is given by:

$$
\begin{aligned}
P_{t} B_{t+1} & +P_{t}\left(1+\tau_{t}^{c}\right)\left[N_{t} C_{t}^{n}+\left(1-N_{t}\right) C_{t}^{u}\right] \\
& \leq P_{H t}\left(1-\tau_{t}^{w}\right) w_{t} h_{t} N_{t}+\left(1-N_{t}\right) P_{H t}\left(1-\tau_{t}^{w}\right) b_{t}+P_{t} B_{t}\left(1+i_{t}^{F}\right)+T_{t}+\pi_{t}
\end{aligned}
$$

The real wage $w_{t}$ and unemployment benefits $b_{t}$ are assumed to be paid in terms of locally produced goods. Both labor revenues and unemployment benefits are taxed at the employee tax rate $\tau^{w}$. $T_{t}$ is a lump-sum transfer from the government and $\pi_{t}$ are lump-sum dividends remitted by firms. Each period, a risk-free interest rate bond is issued (in terms of the consumption bundle); when bought in period $t$, it yields a rate of return $i_{t}^{F}$ in $t+1$. The period's resources are used for consumption expenditures and demand for international assets $\left(B_{t+1}\right)$. Consumption expenditures are subject to indirect taxation with $\tau_{t}^{c}$ the consumption tax rate. Notice the relative price effect in the budget constraint: Consumers care about the consumption basket valued at the consumer price index $P_{t}$ while the wage and unemployment benefits are paid in terms of home goods whose price is $P_{H t}$. 
With $\lambda_{t}$ the shadow price of the budget constraint, the first order conditions with respect to consumption and international bonds are respectively:

$$
\begin{aligned}
\frac{1}{C_{t}^{n}} & =\frac{1}{C_{t}^{u}}=\left(1+\tau_{t}^{c}\right) \lambda_{t} P_{t} \\
P_{t} \lambda_{t} & =\beta\left[\left(1+i_{t+1}^{F}\right) \lambda_{t+1} P_{t+1}\right]
\end{aligned}
$$

The assumption of complete insurance markets combined to separability between consumption and leisure in the instantaneous utility function imply identical optimal consumption levels between family members, whatever their employment status. From now on, we will only consider the aggregate consumption level $C_{t}$.

The intratemporal program Aggregate current consumption $\left(C_{t}\right)$ is spread over domestic goods $\left(C_{H t}\right)$ and imports $\left(C_{F t}\right)$, given CES preferences with elasticity of substitution $\eta$ :

$$
C_{t}=\left[\xi^{\frac{1}{\eta}} C_{H t}^{\frac{\eta-1}{\eta}}+(1-\xi)^{\frac{1}{\eta}} C_{F t}^{\frac{\eta-1}{\eta}}\right]^{\frac{\eta}{\eta-1}} \quad \eta>1
$$

Each period, the household optimizes the consumption bundle (9) subject to the following constraint:

$$
P_{t} C_{t}=P_{H t} C_{H t}+P_{F t} C_{F t}
$$

with $P_{H t}$ and $P_{F t}$ the prices of the domestic and foreign goods respectively, and $P_{t}$ the associated consumer price index. Solving this program leads to the standard optimal demand functions for the domestic and foreign varieties respectively:

$$
\begin{aligned}
C_{H t} & =\xi\left[\frac{P_{H t}}{P_{t}}\right]^{-\eta} C_{t} \\
C_{F t} & =(1-\xi)\left[\frac{P_{F t}}{P_{t}}\right]^{-\eta} C_{t}
\end{aligned}
$$

with the consumption price index $(\mathrm{CPI})$ a function of national goods prices:

$$
P_{t}=\left[\xi P_{H t}^{1-\eta}+(1-\xi) P_{F t}^{1-\eta}\right]^{\frac{1}{1-\eta}}
$$

\subsection{Firms}

There are many identical firms in the economy producing an homogeneous good of price $P_{H}$. Each firm has access to a Cobb-Douglas production technology to produce output:

$$
Y_{t}=A K_{t}^{\alpha}\left(N_{t} h_{t}\right)^{1-\alpha}, \quad 0<\alpha<1
$$


$A$ is the global productivity of factors in the economy (assumed to be constant), $K_{t}$ the physical capital stock, $N_{t}$ the firm's employment level and $h_{t}$ the number of worked hours per employee. The law of motion of physical capital is standard:

$$
K_{t+1}=(1-\delta) K_{t}+I_{t}
$$

with $0<\delta<1$ the capital depreciation rate and $I_{t}$ aggregate investment. To preserve homogeneity in aggregate demand, investment is assumed to be a CES aggregator with the same elasticities of substitution as the consumption basket (equation (9)). In addition, investment is subject to quadratic adjustment costs:

$$
A C_{K t}=\frac{\phi_{K}}{2} \frac{\left(K_{t+1}-K_{t}\right)^{2}}{K_{t}}, \quad \phi_{K}>0
$$

On the labor market side, search frictions require firms to post vacant jobs to be matched by unemployed workers. Accordingly, each firm chooses a number $V_{t}$ of job vacancies, the unit cost of maintaining an open vacancy being $\bar{\omega}$. Hence, a firm's labor employment evolves as:

$$
N_{t+1}=(1-s) N_{t}+q_{t} V_{t}
$$

Firms are subject to direct labor taxation, with $\tau_{t}^{f}$ denoting the payroll tax rate $\left(0<\tau^{f}<1\right)$. Each firm chooses $\left\{V_{t}, N_{t+1}, K_{t+1}, I_{t} \mid t \geq 0\right\}$ to maximize the discounted value of the dividend flow:

$$
\sum_{t=0}^{\infty} \beta^{t} \frac{\lambda_{t+1}}{\lambda_{t}} \pi_{t}
$$

with $\quad \pi_{t}=P_{H t} Y_{t}-P_{t} I_{t}-P_{t} \bar{\omega} V_{t}-P_{H t}\left(1+\tau_{t}^{f}\right) w_{t} N_{t} h_{t}-P_{t} A C_{K t}$

Denoting Tobin's $q_{t}^{k}$ as:

$$
q_{t}^{k}=1+\phi_{K} \frac{K_{t+1}-K_{t}}{K_{t}}
$$

the first-order conditions of the firm's problem are given by:

$$
\begin{aligned}
\frac{\bar{\omega}}{q_{t}} & =\beta\left[\frac{P_{t+1} \lambda_{t+1}}{P_{t} \lambda_{t}}\left\{\frac{P_{H t+1}}{P_{t+1}}(1-\alpha) \frac{Y_{t+1}}{N_{t+1}}-\left(1+\tau_{t+1}^{f}\right) \frac{P_{H t+1}}{P_{t+1}} w_{t+1} h_{t+1}+(1-s) \frac{\bar{\omega}}{q_{t+1}}\right\}\right] \\
q_{t}^{k} & =\beta\left[\frac{P_{t+1} \lambda_{t+1}}{P_{t} \lambda_{t}}\left\{\frac{P_{H t+1}}{P_{t+1}} \alpha \frac{Y_{t+1}}{K_{t+1}}+q_{t+1}^{K}-\delta+\frac{\phi_{K}}{2}\left(\frac{I_{t+1}-\delta K_{t+1}}{K_{t+1}}\right)^{2}\right\}\right]
\end{aligned}
$$

\subsection{Nash bargaining on the labor market}

In presence of labor market search frictions, the match between a worker and a firm gives rise to a rent, that is shared by both players through a bargaining process. We assume that wages and hours are determined via generalized Nash bargaining according to:

$$
\max _{w_{t}, h_{t}}\left(\lambda_{t} \mathcal{V}_{t}^{F}\right)^{\epsilon}\left(\mathcal{V}_{t}^{H}\right)^{1-\epsilon}
$$


with $\mathcal{V}_{t}^{F}$ the marginal value of a match for a firm and $\mathcal{V}_{t}^{H}$ the marginal value for a match for a worker. $\epsilon$ denotes the firm's share of a job's value. The solving of the problem yields worked hours and wage contracts. ${ }^{4}$ The negotiated amount of individual worked hours is given by:

$$
\frac{\sigma_{n} h_{t}^{\eta_{L}}}{\lambda_{t}}=P_{H t}(1-\alpha) \frac{Y_{t}}{h_{t} N_{t}} \frac{1-\tau_{t}^{w}}{1+\tau_{t}^{f}}
$$

The solution for the negotiated wage is given by:

$$
\left(1+\tau_{t}^{f}\right) \frac{P_{H t}}{P_{t}} w_{t} h_{t}=\epsilon\left(1+\tau_{t}^{f}\right)\left[\frac{P_{H t}}{P_{t}} b_{t}-\frac{1}{1-\tau_{t}^{w}} \frac{\Gamma_{t}^{n}-\Gamma_{t}^{u}}{\lambda_{t} P_{t}}\right]+(1-\epsilon)\left[\frac{P_{H t}}{P_{t}}(1-\alpha) \frac{Y_{t}}{N_{t}}+S C_{t}\right]
$$

where $S C_{t}$ denotes search costs:

$$
S C_{t}=\bar{\omega}\left[\frac{1-s}{q_{t}}\left(1-\frac{1+\tau_{t}^{f}}{1+\tau_{t+1}^{f}} \frac{1-\tau_{t+1}^{w}}{1-\tau_{t}^{w}}\right)+e_{t} \theta_{t}\left(\frac{1+\tau_{t}^{f}}{1+\tau_{t+1}^{f}} \frac{1-\tau_{t+1}^{w}}{1-\tau_{t}^{w}}\right)\right]
$$

As shown by Equation (19), with an efficient bargaining over wages and hours, the optimal choice of hours worked by employee is close to the walrasian case (up to payroll tax rates). By contrast, according to Equation (20), the wage contract can be interpreted as a weighted average of the worker's outside option and the marginal product of a match, with the relative weights depending on the relative bargaining powers of both players. Finally, given the sharing rule determined by the Nash program, the optimal search effort level is given by:

$$
\frac{\sigma_{u} e_{t}^{\eta_{L}}}{\lambda_{t}}=\frac{1-\epsilon}{\epsilon} P_{t} \bar{\omega} \theta_{t} \frac{1-\tau_{t+1}^{w}}{1+\tau_{t+1}^{f}}
$$

\subsection{Market equilibria}

Government We rule out public indebtedness by assuming that the government runs a balanced budget each period. The government's budget constraint is thus written as:

$$
P_{t} G_{t}+\left(1-N_{t}\right)\left(1-\tau_{t}^{w}\right) P_{H t} b_{t}+P_{t} T_{t}=\tau_{t}^{c} P_{t} C_{t}+P_{H t}\left(\tau_{t}^{w}+\tau_{t}^{f}\right) w_{t} h_{t} N_{t}
$$

In line with the data, we assume that unemployment benefits $b_{t}$ are a fraction of real wage: $b_{t}=$ $\rho w_{t} h_{t}$ with $\rho$ the unemployment benefit ratio. A higher value of $\rho$ indicates a more generous benefit system. Let us denote $\bar{g}$ ( $\bar{t}$ respectively) the government expenditure (transfers) to GDP ratio $P G / Y(P T / Y)$.

\footnotetext{
${ }^{4}$ Details are provided in Appendix A.2.
} 
Domestic good market The equilibrium condition is given by:

$$
Y_{t}=D_{H t}+D_{H t}^{*}
$$

where $D_{H t}$ and $D_{H t}^{*}$ are the demand functions for the home good coming from the domestic and foreign countries respectively. Given CES preferences that characterize the consumption bundle, but also investment, costs on job posting and public spending (according to Equation (9)), the home demand for home manufactured good is therefore:

$$
D_{H t}=\xi\left[\frac{P_{H t}}{P_{t}}\right]^{-\eta} D_{t}
$$

with aggregate demand $D_{t}=C_{t}+I_{t}+\bar{\omega} V_{t}+A C_{K, t}+G_{t}$. We assume a similar foreign demand function for home manufactured goods, according to:

$$
D_{H t}^{*}=\left(1-\xi^{*}\right)\left[\frac{P_{H t}}{P_{t}^{*}}\right]^{-\eta^{*}} Y^{*}
$$

Domestic exports are a decreasing function of their relative price (with $P_{t}^{*}$ denoting the foreign CPI), while increasing with a foreign demand term $Y^{*}$, that is assumed exogenous and constant, consistently with our small-open economy framework. $1-\xi^{*}$ and $\eta^{*}$ respectively represent the share of home goods and the elasticity between home and foreign varieties in the foreign basket. Accordingly, the foreign CPI is modeled as a weighted average of the home and foreign varieties prices, of functional form:

$$
P_{t}^{*}=\left[\xi^{*} P_{F t}^{1-\eta^{*}}+\left(1-\xi^{*}\right) P_{H t}^{1-\eta^{*}}\right]^{\frac{1}{1-\eta^{*}}}
$$

Current account Taking into account all equilibrium conditions in the household's budget constraint delivers the current account dynamics:

$$
B_{t+1}-\left(1+i_{t}^{F}\right) B_{t}=\frac{P_{H t}}{P_{t}} Y_{t}-D_{t}
$$

International financial asset markets The introduction of incomplete asset markets alters the property of stationarity of the model, since temporary shocks have permanent effects on macroeconomic variables. To preserve the property of stationarity, we follow Kollmann (2002) by assuming that the interest rate at which the household can borrow or lend foreign assets $i_{t}^{F}$, is equal to the exogenous world interest rate $i^{*}$ (assumed to be exogenous and constant) plus a spread, that is a decreasing function of the country's net foreign asset position (expressed in relative terms to GDP):

$$
1+i_{t}^{F}=1+i^{*}-\phi_{b} \frac{P_{t} B_{t}}{P_{H t} Y_{t}} \quad \phi_{b}>0
$$

where $\phi_{b}$ captures the degree of capital mobility (a lower $\phi_{b}$ meaning a higher capital mobility).

In solving the model, we adopt the domestic good as numéraire, such as $P_{H}=1$. All prices should consequently be interpreted in relative terms to the Home good price. 


\section{Optimal fiscal devaluation in a walrasian open-economy}

Our model has two distinctive features: The open-economy dimension and labor market matching frictions. In assessing the implications of fiscal devaluation, we adopt a two-step approach. We first abstract from labor market frictions to consider a small-open walrasian economy. ${ }^{5}$ In this setting, we evaluate the optimal tax reform, both in a long-run perspective and when the transition dynamics is taken into account. Even though simpler, sticking to this walrasian framework presents two noteworthy advantages. First, by preserving analytical tractability, it enables us to provide analytical results about the positive and normative implications of fiscal devaluation. In particular, it allows to analytically demonstrate the key role of the open-economy dimension in shaping the optimal tax design. Second, it allows a direct comparison with the results of Prescott (2004). We will further contrast these results with an economy featured by labor market frictions in the following section, where numerical approach is necessary, even for the steady state analysis.

\subsection{The long-run effects of fiscal devaluation: Analytical insights}

Our first contribution is to provide analytical results about the positive and normative effects of fiscal devaluation. We are able to do so in a simplified framework, that abstracts from labor market frictions. In this walrasian setting, we study the long-run effects of the tax reform, ie. focusing on the steady-state of the model. In solving the long run of the economy, we assume a zero trade balance. $^{6}$ By preserving analytical tractability, this assumption enables us to make the model's mechanisms more transparent, while maintaining the relevance of our fiscal policy analysis. Note that we allow for trade balance deficit or surplus when deriving the transitional dynamics associated with the tax reform.

\subsubsection{Comparing the tax bases}

One key argument that underlies the potential gains from the tax reform relates to tax bases. This is made clear in Proposition $1 .^{7}$

Proposition 1. In the walrasian economy, for $\tau^{x} \geq 0, \forall x=c, w, f$, if $1>\mu \equiv \frac{1-\alpha}{1-\frac{\delta \alpha \beta}{1-\beta(1-\delta)}-\bar{g}}$ then the consumption tax base $(P C / Y)$ is larger than the wage tax base (wh/Y). Provided this holds, we have that $d \tau^{c}<-d \tau^{f}$. This implies that fiscal devaluation reduces the overall tax distortion. Equivalently, defining the tax wedge as $T W \equiv \frac{\left(1+\tau^{c}\right)\left(1+\tau^{f}\right)}{1-\tau^{w}}$, the condition $\mu<1$ ensures the tax wedge reduces with fiscal devaluation.

\footnotetext{
${ }^{5}$ The walrasian model (in both the closed- and the open-economy cases) is detailed in Section B of the Appendix.

${ }^{6}$ This is also the case in the model with labor market frictions.

${ }^{7}$ Details about the proof are reported in Subsection B.3.2 of the Appendix.
} 
Proof. The tax base enlargment condition is straightforward using the government's budget constraint (22) in a walrasian economy. Holding $\{\bar{g} ; \bar{t}\}$ constant, and given the long-run values of $P C / Y$ and $w h / Y$ (See Equations $O W 2-O W 3-O W 6$ in Appendix B.2), it comes that $C / Y>w h / Y \Leftrightarrow$ $1+\tau^{f}>\mu$. By differentiating Equation (22) around this steady-state, we obtain that:

$$
d \tau^{c}=\frac{-\left(1-\tau^{w}\right) \mu}{\left(1+\tau^{f}\right)^{2}} d \tau^{f}
$$

Thus, for $\tau^{x} \geq 0, \forall x=w, f, \mu<1$ is a sufficient condition for $d \tau^{c}<-d \tau^{f}$.

Consider now the effect on overall tax distortion (ie, the tax wedge $T W$ ). Using Equation (25),

we then have that $\frac{d T W}{d \tau^{f}}=\frac{\frac{\left(1+\tau^{c}\right)\left(1+\tau^{f}\right)}{1-\tau^{w}}-\mu}{1+\tau^{f}}$. Thus, for $\tau^{x} \geq 0, \forall x=c, w, f, \mu<1$ is a sufficient condition to have $d T W<0$ after a fiscal devaluation.

This result is directly related to one key argument behind fiscal devaluation, which relies on the tax base comparison. Provided that the consumption tax base is larger than the wage tax base $(C / Y>w h N / Y)$, the switch from direct labor taxation to indirect taxation inherent to fiscal devaluation, makes it possible to compensate the reduction in payroll taxation by a less than proportional increase in the indirect tax rate, for a given ratios of government expenditures and transfers. As a related consequence, fiscal devaluation reduces the overall tax burden. In what follows, we always consider this case. For the case with search frictions, we assume that this property is also satisfied. Indeed, if it is not the case, fiscal devaluation is trivially inefficient.

\subsubsection{Fiscal devaluation and worked hours}

We here evaluate how fiscal devaluation affects labor market performances. To anticipate on our results, the amount of hours worked is governed by the trade-off between consumption (taxed) and leisure (not taxed) with respect to the marginal returns of the labor (taxed). Thus, there is explicitly the option of not paying taxes, implying that the fiscal reform has a direct effect on this trade-off. This is made clear by the long-run value for worked hours, which can be expressed as:

$$
h=\left(\frac{1-\tau^{w}}{\left(1+\tau^{c}\right)\left(1+\tau^{f}\right)} \frac{1-\alpha}{\sigma_{n}\left(1-\frac{\alpha \beta \delta}{1-\beta(1-\delta)}-\bar{g}\right)}\right)^{\frac{1}{1+\eta_{L}}}
$$

This equation also drives two main comments. The first one relates to tax bases. Equation (26) indicates that fiscal devaluation would have virtually no impact on worked hours if $d \tau^{c}=-d \tau^{f}$. Nevertheless, Proposition 1 states that the tax reform implies a less-than-proportional increase in the indirect tax rate, ie $d \tau^{c}<-d \tau^{f}$. Provided it holds, we infer from Equation (26) that fiscal devaluation raises worked hours because of a tax base enlargement.

The second comment is linked to the open-economy dimension $(P \neq 1)$. Given our utility function, the substitution effect is compensated by wealth effect, implying that the changes in 
relative prices has no direct effect on worked hours (as shown in Equation (26)). Otherwise said, the worked hours adjustment after fiscal devaluation is the same as would prevail in the closedeconomy case. ${ }^{8}$ Yet, as we shall see, it crucially matters by affecting welfare via the consumption dynamics.

\subsubsection{The role of the open-economy dimension}

Given the model's equations, the assumption of a zero trade balance in the long run $D_{H}^{*}=P_{F} D_{F}$ can be rewritten as:

$$
\left(1-\xi^{*}\right)\left[\xi^{*} P_{F}^{1-\eta^{*}}+1-\xi^{*}\right]^{\frac{\eta^{*}}{1-\eta^{*}}} Y^{*}=\left[\frac{(1-\xi) P_{F}^{1-\eta}}{\xi+(1-\xi) P_{F}^{1-\eta}}\right] Y
$$

with the long-run values of $Y$ and $P$ given by: ${ }^{9}$

$$
\begin{aligned}
Y & =A^{\frac{1}{1-\alpha}}\left[\frac{\alpha \beta}{1-\beta(1-\delta)}\right]^{\frac{\alpha}{1-\alpha}} P^{\frac{-\alpha}{1-\alpha}} h \\
P & =\left[\xi+(1-\xi) P_{F}^{1-\eta}\right]^{\frac{1}{1-\eta}}
\end{aligned}
$$

From Equation (27), we can derive the impact of the tax reform on $P_{F}$.

Proposition 2. In a frictionless labor market, the impact of fiscal devaluation on $P_{F}$ goes only through the change in $h$. If fiscal devaluation leads to a increase in $h$, then $P_{F}$ increases, so does $P$.

Proof. Manipulating Equations (27), (28) and (29) allows to express the zero trade balance condition as a function of the two variables $h, P_{F}:{ }^{10}$

$$
\Psi=\varphi\left(P_{F}\right) f\left(P_{F}\right) g\left(P_{F}\right) h
$$

with $\Psi$ a constant term and $\varphi^{\prime}<0, f^{\prime}<0$ and $g^{\prime}<0$. Differentiation this, we can deduce that:

$$
\begin{array}{ll} 
& \frac{d h}{h}=\frac{d P_{F}}{P_{F}}\left[\eta^{*} f^{*}\left(P_{F}\right)+(\eta-1)\left(1-f\left(P_{F}\right)\right)+\frac{\alpha}{1-\alpha} f\left(P_{F}\right)\right] \\
\text { with } \quad f\left(P_{F}\right) & \equiv \frac{(1-\xi) P_{F}^{1-\eta}}{\xi+(1-\xi) P_{F}^{1-\eta}} \\
\text { and } \quad f^{*}\left(P_{F}\right) \equiv \frac{\xi^{*} P_{F}^{1-\eta^{*}}}{\xi+(1-\xi) P_{F}^{1-\eta^{*}}+1-\xi^{*}}
\end{array}
$$

It is straightforward that $0<f\left(P_{F}\right)<1$. Given that $\eta>1$ by assumption, it follows that the term $\left[\eta^{*} f^{*}\left(P_{F}\right)+(\eta-1)\left(1-f\left(P_{F}\right)\right)+\frac{\alpha}{1-\alpha} f\left(P_{F}\right)\right]$ is always positive. This establishes Proposition 2.

\footnotetext{
${ }^{8}$ The same equation (26) also gives the amount of hours worked in a closed economy, as shown in Appendix B.1. ${ }^{9}$ See details in Appendix B.2.

${ }^{10}$ See Appendix B.3 for full details of the proof.
} 
Combining Propositions 1 and 2 implies that, provided that fiscal devaluation raises worked hours (Proposition 1), then the competitiveness of the domestic economy is improved in the long run.

\subsubsection{Fiscal devaluation and welfare}

Fiscal devaluation must be implemented if the reform improves not only labor market outcomes but also agents' welfare. We now study the long-run welfare properties of the tax reform in the walrasian economy.

In closed economy. We first determine the normative implications of the tax reform in the closed-economy setting. In this case, welfare is given by:

$$
(1-\beta) \mathcal{W}=\log (C)-\sigma_{n} \frac{h^{1+\eta_{L}}}{1+\eta_{L}} \quad \text { with }\left\{\begin{aligned}
C & =\left(1-\frac{\delta \alpha \beta}{1-\beta(1-\delta)}-\bar{g}\right) Y \\
Y & =A^{\frac{1}{1-\alpha}}\left(\frac{\alpha \beta}{1-\beta(1-\delta)}\right)^{\frac{\alpha}{1-\alpha}} h
\end{aligned}\right.
$$

The welfare function defines a potential trade-off: fiscal devaluation increases consumption but also decreases leisure. Proposition 3 identifies the sufficient condition for the reform to be welfareimproving.

Proposition 3. Fiscal devaluation unambiguously increases welfare in a closed walrasian economy if $\left(1+\tau^{c}\right) C>\left(1-\tau^{w}\right)$ wh. For positive tax rates, a sufficient condition is then $\mu<1$.

Proof. Using (33), it comes that $(1-\beta) \frac{d \mathcal{W}}{d h}=\frac{1}{h}-\sigma h^{\eta_{L}}$. We deduce that $\frac{d \mathcal{W}}{d h}>0$ iff, $\frac{1}{h}>$ $\sigma_{n} h^{\eta_{L}} \Leftrightarrow 1>\sigma_{n} h^{\eta_{L}+1}$. Given the first-order conditions on hours worked and consumption that give: $w h=\frac{1+\tau^{c}}{1-\tau^{w}} \sigma h^{\eta_{L}+1} C$, this condition is equivalent to $\left(1+\tau^{c}\right) C>\left(1-\tau^{w}\right) w h$. Given that Proposition 1 shows that $C>w h$ is sufficient to have $d \tau^{c}<-d \tau^{f}$, thus, if fiscal devaluation increases $h$ (Proposition 1), it continuously improves welfare.

Combining Proposition 1 and 3 implies that tax base enlargement (ie, $C / Y>w h / Y$ ) is a sufficient condition for fiscal devaluation to be welfare-improving in a closed walrasian economy.

In the open economy. Welfare is given by:

$$
(1-\beta) \mathcal{W}=\log (C)-\sigma_{n} \frac{h^{1+\eta_{L}}}{1+\eta_{L}} \quad \text { with }\left\{\begin{aligned}
C & =\left(1-\frac{\delta \alpha \beta}{1-\beta(1-\delta)}-\bar{g}\right) \frac{Y}{P} \\
Y & =A^{\frac{1}{1-\alpha}}\left(\frac{\alpha \beta}{1-\beta(1-\delta)}\right)^{\frac{\alpha}{1-\alpha}} P^{\frac{-\alpha}{1-\alpha}} h
\end{aligned}\right.
$$

Notice that output and consumption in the open economy model are the same as in the closed economy setting, except for the presence of the relative price effect captured by $P$. As $P$ monotonically 
increases with $P_{F}$ (Equation (64)) and given Proposition 2, we infer that fiscal devaluation has two contrasting effects on consumption. On the one hand, fiscal devaluation induces a positive wealth effect, as in the closed-economy case. By increasing worked hours, output and real wages, fiscal devaluation exerts an upward pressure on consumption, hence welfare (despite the larger disutility of work). On the other hand, in an open-economy framework the tax reform induces a detrimental relative price effect, that conversely tends to lower consumption. As the consumption price index increases with the tax reform (due to the rise in import prices, Proposition 2), the purchasing power of real wages goes down. The open-economy dimension does matter due to this relative price effect on consumption, whose magnitude is determined by the trade balance adjustment (Equation (27)). Proposition 4 states the condition under which the tax reform is welfare-improving in the open walrasian economy. ${ }^{11}$

Proposition 4. Fiscal devaluation increases welfare in an open walrasian economy if $\Upsilon\left(P_{F}\right) \frac{\left(1+\tau^{c}\right)\left(1+\tau^{f}\right)}{1-\tau^{w}}>$ $\mu$, with $\Upsilon\left(P_{F}\right)$ such that $\Upsilon\left(P_{F}\right) \in[0,1]$ and $\Upsilon^{\prime}\left(P_{F}\right)<0$.

Proof. Expression (34) leads to:

$$
(1-\beta) \frac{d \mathcal{W}}{d h}=\frac{1}{h}\left[1-\frac{1}{1-\alpha} f\left(P_{F}\right) \frac{d P_{F} / P_{F}}{d h / h}\right]-\sigma_{n} h^{\eta_{L}} \equiv \frac{1}{h} \Upsilon\left(P_{F}\right)-\sigma_{n} h_{L}^{\eta}
$$

where $\frac{d P_{F} / P_{F}}{d h / h}$ is determined according to Equation (B.3.3).

Given the definition of $\Upsilon\left(P_{F}\right)$, it comes that $(1-\beta) \frac{d \mathcal{W}}{d h}=\frac{1}{h} \Upsilon\left(P_{F}\right)-\sigma_{n} h^{\eta_{L}}$. Then, we have that $(1-\beta) \frac{d \mathcal{W}}{d h}>0$ if $\frac{1}{h} \Upsilon\left(P_{F}\right)>\sigma_{n} h_{L}^{\eta} \Leftrightarrow \Upsilon\left(P_{F}\right)>\sigma_{n} h^{1+\eta_{L}}$. This expression shows that a necessary condition for $(1-\beta) \frac{d \mathcal{W}}{d h}>0$ is $\Upsilon\left(P_{F}\right)>0$. This condition is satisfied if $f\left(P_{F}\right)<\frac{\eta-1}{\eta}$. If this condition is satisfied, the sufficient condition for $\frac{d \mathcal{W}}{d h}>0$ is thus $\Upsilon\left(P_{F}\right) \frac{\left(1+\tau^{c}\right)\left(1+\tau^{f}\right)}{1-\tau^{w}}>\mu$.

This last result suggests that an optimal fiscal scheme can exist, but the open-economy dimension reduces its efficiency. This is illustrated in Figure 1.

The x-axis of Figure 1 displays total fiscal distortion $T W=\frac{\left(1+\tau^{c}\right)\left(1+\tau^{f}\right)}{1-\tau^{w}}$. The upward sloping $\Upsilon\left(P_{F}\right) \frac{\left(1+\tau^{c}\right)\left(1+\tau^{f}\right)}{1-\tau^{w}}$ and the flat line $\mu$, are both reported as a function of total fiscal distortion on the y-axis. Under Proposition 1, fiscal devaluation reduces $T W$ (from the benchmark economy, moving to the left along the $\mathrm{x}$-axis in Figure 1). As established by Proposition 4, fiscal devaluation is welfare improving as long as $\Upsilon\left(P_{F}\right) \frac{\left(1+\tau^{c}\right)\left(1+\tau^{f}\right)}{1-\tau^{w}}>\mu$, which defines a set of possible welfare improving values. When this condition does not hold, which happens for a (too) large fiscal devaluation (a greater fall in $\frac{\left(1+\tau^{c}\right)\left(1+\tau^{f}\right)}{1-\tau^{w}}$ starting from the benchmark value), the change in the tax scheme can actually decrease welfare. Since the relative price of foreign goods $P_{F}$ and the consumption price index $P$ rise following fiscal devaluation, this exerts a downward pressure on aggregate consumption. The

\footnotetext{
${ }^{11}$ See Appendix B.3.
} 
Figure 1: Existence of an optimal fiscal devaluation scheme

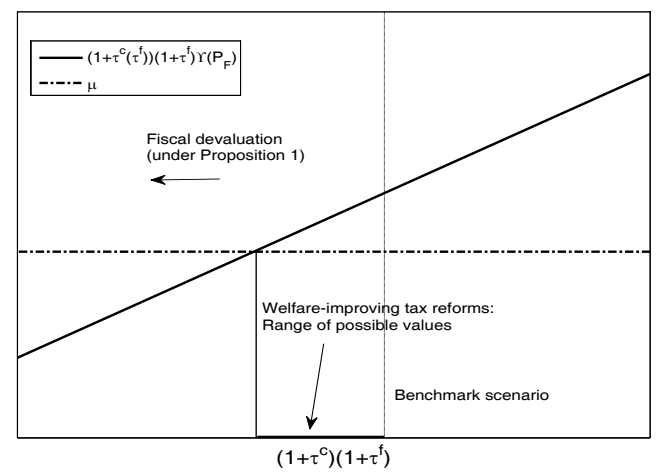

open-economy dimension thus introduces an hump-shaped welfare function, with a maximum that defines the optimal fiscal devaluation: The peak of the welfare curve is reached for $\frac{\left(1+\tau^{c}\right)\left(1+\tau^{f}\right)}{1-\tau^{w}}$ located at the intersection of $\Upsilon\left(P_{F}\right) \frac{\left(1+\tau^{c}\right)\left(1+\tau^{f}\right)}{1-\tau^{w}}$ and $\mu$.

\subsection{Taking into account the transition dynamics}

Our results therefore put into evidence the key role of the open-economy dimension in shaping the optimal tax design. In a pure walrasian economy, fiscal devaluation faces a trade-off between improving labor market performances and penalizing the agents' purchasing power. This tradeoff gives rise to a hump-shape welfare curve in the long run. We now investigate this point in quantitative terms. This first requires to calibrate the model.

\subsubsection{Some words on calibration}

Given that we ultimately want to model an economy with labor market frictions, we consider France as a benchmark economy, as it exemplifies a rigid labor market (and even though we abstract from them in this section). We thus proceed to a careful calibration of the model's deep parameters. We briefly describe here our calibration strategy (full details are provided in Section $\mathrm{C}$ of this paper, and summarized in Tables 5 and 6 for the walrasian economy). In a fist step, we estimate a sub-set of deep parameters to make the artificial economy consistent with the main empirical features of the French economy. In particular, we pay attention to match the tax base difference in consumption and payroll taxes. In a second step, given these deep parameters' values, we evaluate the implications of the tax reform on the main macroeconomic variables, starting from the benchmark initial calibration with the tax scheme $\left\{\tau^{f}=0.34, \tau^{c}=0.22, \tau^{w}=0.13\right\}$. We model fiscal devaluation by assuming a permanent given reduction in the payroll tax rate, the employee's 
tax rate being maintained constant. ${ }^{12}$ We then derive the endogenous value of the indirect tax rate $\tau^{c}$ at the general equilibrium of the model, that is notably consistent with the government's budget constraint (22) for constant values of the ratios of public spending $\bar{g}$ and transfers $\bar{t}$ (relative to GDP). This experiment is consistent with the budget neutrality inherent to fiscal devaluation.

We adopt the same calibration strategy for the model with labor market frictions (See Appendix C, Tables 1 and 2). Note however, that we adopt a different calibration of the labor supply elasticity between the two models. Indeed, labor market frictions are by nature absent from the walrasian setting. As a related consequence, given that all the workforce is employed $(N=1)$, all changes in labor input occur along the intensive margin (worked hours $h$ ). This drives us to retain a larger labor supply elasticity in the walrasian model. Precisely in that case, we follow Prescott (2004) and calibrate the parameters $\left(\sigma_{n}, \eta_{L}\right)$ so as to replicate a log-specification on leisure. ${ }^{13}$

\subsubsection{Optimal tax policy in the long run}

We first determine the optimal tax scheme in the long run, ie focusing on the comparison of steady states. In the spirit of Lucas (1987) and Lucas (2003), we calculate the welfare gain associated with a given tax reform, by comparing two economies both starting from the initial steady-state (before the tax change). The first economy is not hit by the fiscal reform and remains ad vitam at its initial steady state $\left(C^{0}, h^{0}, \ldots\right)$. By contrast, the second economy is hit by the fiscal shock, with $\left.C^{*}, h^{*}, \ldots\right)$ representing the new final steady state. We then determine the compensation, that should be given to the agents for them to accept to stay in the economy without reform. Precisely, we determine the long-run gain/loss of a given reform by deriving the compensation $\phi^{L R}$ such as:

$$
\mathcal{W}\left[\left(1+\phi^{L R}\right) C^{0}, h^{0}\right]=\mathcal{W}^{*}\left[C^{*}, h^{*}\right]
$$

A positive (negative) value of $\phi^{L R}$ means that the reform is welfare-improving (welfare-deteriorating). To determine the optimal tax policy, we derive the values of $\phi^{L R}$ associated with a various range of tax rates $\left(\tau^{f}, \tau^{c}\right)$, the optimal tax scheme being reached when $\phi^{L R}$ is maximized. Results are reported in Figure 2.

In accordance with our analytical results (Proposition 4), the welfare curve displays a humpshape behavior. Starting from the benchmark value of $\tau^{f}=0.34$, fiscal devaluation first improves welfare by reducing fiscal distortions. The rise in consumption dominates the increase in the disutility of work. For a larger magnitude of fiscal devaluation though (moving leftwards on the x-axis),

\footnotetext{
${ }^{12}$ In Section 4.2 .2 , we alternatively consider a reduction in the employee's tax rate, the payroll tax rate being constant. We show that this does not change the results.

${ }^{13}$ In the log-utility case, labor supply elasticity is equal to $(1-h) / h$. With $h$ the steady-state amount of worked hours equal to $h=1 / 3$, this implies a labor supply elasticity of 2.33 . We replicate the case of a log-specification on leisure with our more general specification (Equation (3)). This implies a value of $\eta_{L}=1 / 2.33=0.429$ and $\sigma_{n}=3.62$. By contrast, calibration of the search model implies a much lower elasticity of worked hours, around 0.5. See Tables 3 and 6 .
} 
Figure 2: Optimal fiscal devaluation at the steady state (Walrasian economy)

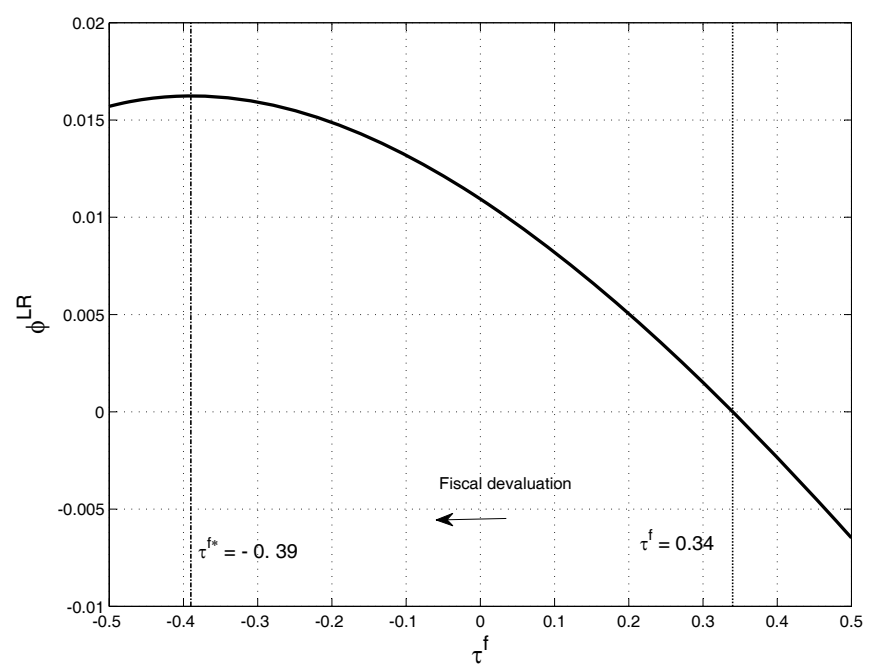

the competitive effect exerts a downward pressure on consumption. The purchasing power of wages is eroded by the increase in the home price index, itself attributable to the rise in the relative price of imports. With a more significant fall in $\tau^{f}$, this effect tends to dominate, thereby leading to a decreasing welfare. In quantitative terms yet, the negative relative price effect never dominates for positive values of the tax rate, as the optimal tax scheme is $\left\{\tau^{f \star}=-0.39, \tau^{c \star}=1.06\right\}$.

\subsubsection{Taking into account the dynamics of the tax reform}

The previous analysis neglects the transition dynamics of the tax reform, yet necessary to reach the new steady state. We now take this dimension explicitly into account, and modify the calculus of the compensation accordingly. Let denote $\left\{C_{t}^{*}, h_{t}^{*}\right\}_{t=0}^{\infty}$ the paths of consumption and worked hours in the economy hit by the reform. The welfare gain (or loss) of a given reform is given by the compensation $\phi$ such as:

$$
\mathcal{W}\left[\left\{(1+\phi) C^{0}, h^{0},\right\}_{t=0}^{\infty}\right]=\mathcal{W}^{*}\left[\left\{C_{t}^{*}, h_{t}^{*}\right\}_{t=0}^{\infty}\right]
$$

We then derive the values of $\phi$ associated to a various range of tax schemes. Again, the optimal tax reform (transition included) is reached when $\phi$ is maximized. Results are reported in Figure 3.

As in the long-run comparison (Figure 2), we obtain a hump-shaped welfare curve of the tax reform. Quantitative results are much different though. Starting from the benchmark current tax policy $\left(\tau^{f}=0.34\right.$ and $\tau^{c}=0.22$ ), the optimal tax reform is reached for $\tau^{f \star}=0.43$ (and $\left.\tau^{c \star}=0.18\right)$. With the transition dynamics included, the optimal tax reform is an "anti-fiscal" devaluation. Equivalently, this results states that it is optimal to raise the overall tax distortion in 
Figure 3: Optimal tax reform, with transition included (Walrasian economy)

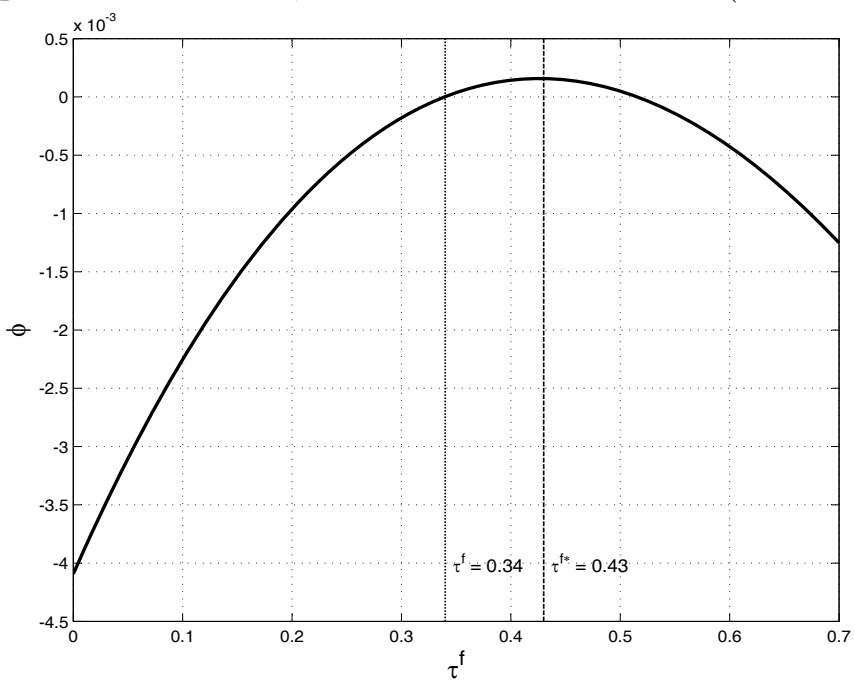

the economy. This result stands in sharp contrast with the optimal long-run policy $\tau^{f \star}=-0.39$ and $\tau^{c \star}=1.06$ in Figure 2).

Comparing Figures 2 and 3 thus illuminates the result that transition crucially matters. Precisely, transition is costly, and the costs are large. It is indeed costly in the short run to work and save in order to reach the (higher) level of capital which characterizes the final steady state. In order to compensate for these transitional costs, the final steady state must insure the agents against the purchasing power losses, thus calling for a limited (and even reversed) relative price effect in the long run. As depicted in Figure 3, even if fiscal devaluation can be welfare-improving in the long run (Figure 2), these potential gains may not compensate the short-run effort necessary for the accumulation process. Thus, when the promise of a better economy in the long run is not sufficiently valued by the agents, the optimal reform (transition included) is rather to consume more in the short run and to less participate at the exchanges on the labor market. The optimal fiscal policy is biased against working. Accordingly, the optimal tax policy consists in an "anti-fiscal devaluation".

In this respect, our results strongly contrast those obtained by Prescott (2004) in a walrasian (but closed) economy setting. According to Prescott (2004), a 20-point reduction in tax pressure would yield welfare gains of $19 \%$ in terms of lifetime consumption equivalents for the (French) economy, with the transitional costs of the reform included. By contrast, in our setting a 20-point reduction in the payroll tax rate $\tau^{f}$ implies a reduction of welfare equal to $0.17 \%$ in terms of lifetime consumption equivalents. This is a striking difference of results, that can be accounted for by two main reasons. First, Prescott (2004) and us do not consider the same tax reform. In his view, the reduction in proportionary taxes is compensated by an increase in lump-sum taxation (which has no distorsive 
effect) while maintaining the level of public spending constant. Given that output increases with the tax reform, this implies a reduction in the ratio of public spending to output, thereby reducing the crowding-out effect on private consumption. By contrast, fiscal devaluation is designed so as to preserve the welfare state programs, ie with constant ratios of public spending and transfers relative to GDP. This difference of budgetary adjustment undoubtedly mitigates the reduction of tax distortions induced by fiscal devaluation reform in comparison with Prescott's exercise, hence the welfare gain associated to the tax reform. Second, this effect is strengthened by our inclusion of the open-economy dimension. The relative price effect of fiscal devaluation makes the tax reform potentially too costly, an effect which cannot be taken into account in Prescott's exercise given its closed-economy framework. Both arguments combine to explain the much lower, and even negative welfare effects of fiscal devaluation that we consider. This comparison thus illuminates the inherent difficulty of designing an optimal tax reform, as long as the agents are attached to the maintaining of the welfare state while operating in an open world.

\section{Optimal fiscal devaluation and labor market frictions}

As first contribution, we have shown that fiscal devaluation is not efficient in a walrasian open economy. Nevertheless, European labor markets are characterized by large frictions on the labor market. These additional distortions may give some additional argument to such a policy, one intuitive argument being that fiscal devaluation contributes to alleviate the tax burden on labor input. In this section, we therefore address the question of the optimality of fiscal devaluation when labor market search frictions are embodied in the model. In what follows, we always consider that Proposition 1 is satisfied: The tax bases argument leads fiscal devaluation to reduce the overall tax distortion. We first present the main differences with the walrasian model by relying on analytical results of the model's long-run properties. We then characterize the optimal fiscal devaluation scheme in quantitative terms, using France as benchmark economy.

\subsection{Some analytical insights}

In this section, we provide some analytical intuition on how fiscal devaluation affects labor market performances in a non-walrasian economy. Even though the model becomes too complex to derive any general equilibrium result on the tax reform effects (even in the long run), we find it useful to derive some partial analytical results, notably in comparison with the walrasian case. In particular, we decompose the impact of the tax reform on the intensive margin of labor input (hours worked and search effort) and the extensive margin (employment level). 
Worked hours. In presence of search frictions, worked hours are given by: ${ }^{14}$

$$
h=\left(\frac{1}{N} \frac{1-\tau^{w}}{\left(1+\tau^{c}\right)\left(1+\tau^{f}\right)} \frac{1-\alpha}{\sigma_{n}\left(1-\frac{\alpha \beta \delta}{1-\beta(1-\delta)}-\bar{g}-\frac{P \bar{\omega} s \theta^{1-\psi}}{\chi Y / N}\right)}\right)^{\frac{1}{1+\eta_{L}}}
$$

As in the walrasian case, fiscal devaluation directly affects the trade-off between consumption and leisure. Everything else equal under Proposition 1, ie $d \tau^{c}<-d \tau^{f}$, fiscal devaluation raises worked hours because of a tax base enlargement. However, things are no longer everything else equal. Unlike the walrasian case, the employment level and the price index now intervene in the long-run value of worked hours, such that the equilibrium worked hours can only be obtained at the general equilibrium.

The employment level. In presence of labor market frictions, the employment level in the labor market flow equilibrium is given by:

$$
N=\frac{e \chi \theta^{\psi}}{s+e \chi \theta^{\psi}}<1
$$

The equilibrium employment is a function of labor market tightness $\theta$ and search effort $e$. Note that at the first-rank allocation, obtained when $\tau^{f}=\tau^{c}=\rho=0$ and $\epsilon=\psi$ (the so-called Hosios conditions), Equation (36) delivers the optimal employment level through the optimal values of $\theta$ and $e$.

- The labor market tightness. It is derived from the firms' labor demand for a given bargained wage:

$$
\theta^{1-\psi} \frac{\bar{\omega}}{\chi}=\frac{\beta \epsilon}{(1-\epsilon \rho)(1-\beta(1-s))} \frac{\eta_{L}}{\left(1+\eta_{L}\right)}\left[\left(1-\rho-\frac{\rho}{\eta_{L}}\right) \frac{(1-\alpha) Y / N}{P}-\frac{1-\epsilon}{\epsilon} \bar{\omega} e \theta\right]
$$

Labor market tightness at the first-best allocation can be uncovered from Equation (37) (recalling that in that case $\tau^{f}=\tau^{c}=\rho=0$ and $\epsilon=\psi$ ):

$$
\theta^{1-\psi} \frac{\bar{\omega}}{\chi}=\frac{\beta \psi}{(1-\beta(1-s))} \frac{\eta_{L}}{\left(1+\eta_{L}\right)}\left[\frac{(1-\alpha) Y / N}{P}-\frac{1-\psi}{\psi} \bar{\omega} e \theta\right]
$$

The larger the gap between the first-best allocation (38) and the decentralized allocation (37), the larger the room for fiscal policy, such as fiscal devaluation. In this respect, Equation (37) drives two main comments. First, it is interesting to note that, unlike worked hours, tax policy does not have a direct impact on labor market tightness. This is attributable to the fact that

\footnotetext{
${ }^{14}$ See details on the long-run equilibrium of the search economy in Section A.4. of the Appendix.
} 
all components of the reservation wage are proportional to the wage. ${ }^{15,16}$ The effects of the tax reform on $\theta$ are thus channeled indirectly through general equilibrium effects. Second, the (general equilibrium) effects of tax policy on labor market tightness are affected by the set of labor market institutions (through $\epsilon$ or $\rho$ ). This result contributes to make us investigate the sensitivity of the optimal tax reform to the labor market institutions.

- The incentive to look for a job. The tax reform may indeed improve labor market outcomes by enticing unemployed workers to provide the optimal search effort. In the decentralized economy, the long-run unemployed search effort is given by:

$$
e=\left(\frac{1-\tau^{w}}{\left(1+\tau^{c}\right)\left(1+\tau^{f}\right)} \frac{1-\epsilon}{\epsilon} \frac{\frac{P \bar{\omega} \theta}{Y}}{\sigma_{u}\left(1-\frac{\delta \alpha \beta}{1-\beta(1-\delta)}-\bar{g}-\frac{P \bar{\omega} s \theta^{1-\psi}}{\chi^{Y / N}}\right)}\right)^{\frac{1}{\eta_{L}}}
$$

At the first-best (Hosios) allocation, we have:

$$
e=\left(\frac{1-\psi}{\psi} \frac{\frac{P \bar{\omega} \theta}{Y}}{\sigma_{u}\left(1-\frac{\delta \alpha \beta}{1-\beta(1-\delta)}-g-\frac{P \bar{\omega} s \theta^{1-\psi}}{\chi Y / N}\right)}\right)^{\frac{1}{\eta_{L}}}
$$

As for worked hours, Equation (39) indicates that the tax scheme has a direct effect on the search effort. Since fiscal devaluation implies a less-than-proportional increase in the indirect tax rate, ie $d \tau^{c}<-d \tau^{f}$, the tax reform raises search effort, therefore the job finding rate. Fiscal devaluation can then be useful to reduce the gap between the decentralized allocation and the first-best allocation, as long as it is too low in the decentralized equilibrium.

The role of the open-economy dimension. In steady-state, the trade balance equilibrium condition can be expressed as:

$$
\left(1-\xi^{*}\right)\left[\xi^{*} P_{F}^{1-\eta^{*}}+1-\xi^{*}\right]^{\frac{\eta^{*}}{1-\eta^{*}}} Y^{*}=\left[\frac{(1-\xi) P_{F}^{1-\eta}}{\xi+(1-\xi) P_{F}^{1-\eta}}\right] A^{\frac{1}{1-\alpha}}\left[\frac{\alpha \beta}{1-\beta(1-\delta)}\right]^{\frac{\alpha}{1-\alpha}} P^{\frac{-\alpha}{1-\alpha}} h N
$$

with $P$ an increasing function of $P_{F}$ according to Equation (64). The impact of the tax reform on $P_{F}$ now goes through changes in labor input along both the intensive and the extensive margin $(h$ and $N$ ). Unambiguously, the relative price of foreign goods $P_{F}$ will go up as worked hours and the employment level increase with fiscal devaluation. Since the employment response depends on labor market institutions (Equations (36) and (37)), this will also be the case of the competitive effect.

\footnotetext{
${ }^{15}$ The reservation wage is standardly defined as the sum of unemployment benefits and the marginal rate of substitution between employment and consumption.

${ }^{16}$ When unemployment benefits are indexed to the wage, the reservation wage is proportional to the gap between the costs of working and of searching for a job (ie, $\Gamma^{n}-\Gamma^{u}$ ). Given that unemployed workers and employees are similarly taxed, this cost differential is proportional to the gap of the productivities in both activities, and thus independent of the tax system. This can be shown analytically combining Equations (19), (20) and (21) in steady state.
} 
Fiscal devaluation and welfare In comparison with the walrasian framework, it is likely that labor market modify the trade-off faced by the policy maker in designing the optimal tax scheme. By reducing the employment level through labor market tightness and search effort, labor market rigidities can indeed induce an additional dividend to fiscal devaluation: In a economy where the equilibrium level of employment is too low, fiscal devaluation can reduce the structural inefficiencies. This suggests that, in such a context, the optimal tax reform may be of larger magnitude than in the walrasian economy (ie, a larger fall in $\tau^{f}$ starting from the benchmark case). This additional dividend of the reform comes from the gap between the decentralized allocation and the first best allocation obtained when the Hosios conditions are satisfied. The larger the gap on the labor market, the larger this additional dividend of fiscal devaluation.

The complexity of the model does not allow us to provide any clear-cut analytical result at the general equilibrium. This calls for a quantitative assessment, which is made in next section.

\subsection{Optimal fiscal devaluation: A quantitative assessment}

We now evaluate the optimal tax scheme in quantitative terms. To our view, the quantitative exercise has been overlooked in spite of being crucial in the discussion about the relevance of fiscal devaluation. This section contributes to fill this gap.

We retain France as the benchmark country, as it exemplifies a rigid labor market. We implement the same calibration strategy as for the walrasian model (Section 3), as fully detailed in Appendix $\mathrm{C}$ (Tables 1, 2 and 3). As in the walrasian case, we evaluate the implications of the tax reform by starting from the initial steady state featured by $\tau^{c}=0.22, \tau^{f}=0.34$ and $\tau^{w}=0.13$. We then investigate the optimal tax reform in quantitative terms by deriving the compensation $\phi$ associated with varying values of the payroll tax rate $\tau^{f}$ (and the associated indirect tax rate $\tau^{c}$ ).

\subsubsection{Optimal tax reform in presence of search frictions}

Figure 4 reports the welfare effects of fiscal devaluation, i.e. the value of $\phi$, for varying values of the couple $\left(\tau^{f}, \tau^{c}\right)$ in the open labor market search economy (with the transition dynamics of the tax reform included).

As reported in Figure 4, the welfare curve displays a hump-shape behavior. This extends our previous results (Section 3) to an environment with labor market frictions. The welfare effects of the fiscal reform can be understood as the result of two opposite forces. On the one hand, reduced distortions on labor input and the induced positive wealth effect call for fiscal devaluation. On the other hand, the purchasing power parity loss induced by the increase in the relative price of imports, calls for an "anti-fiscal" devaluation. Moreover, echoing our initial guess, the hump shape shifts to the left with labor market frictions: With labor market rigidities, the welfare-maximizing payroll tax 
Figure 4: Optimal fiscal devaluation in the labor search economy

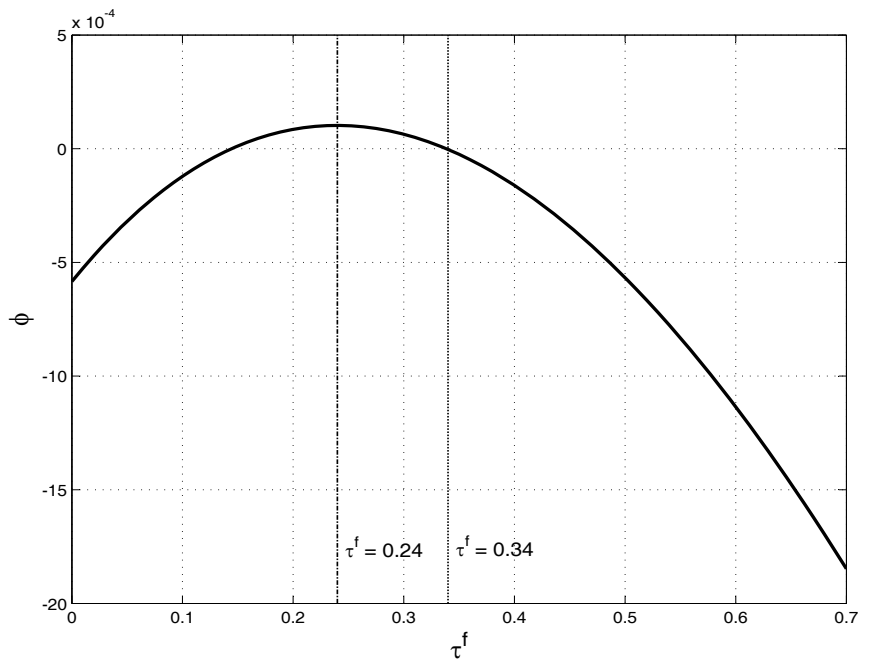

is lower than in the walrasian economy $\left(\tau^{f^{*}}=0.24\right.$ versus $\tau^{f^{*}}=0.43$, with the associated indirect tax rates being respectively $\tau^{c^{*}}=0.28$ vs $\tau^{c^{*}}=0.18$ ). The presence of labor market frictions strengthens the need for a reduced payroll tax rate (in comparison with the walrasian economy), so as to reduce the labor market inefficiency gap. The lower the labor market rigidities, the smaller the gap between the optimal taxation in the walrasian and the search economies.

What are the general equilibrium effects of the optimal tax reform? To investigate this point, we study the positive implications of the optimal tax reform, featured by a once-and-for all reduction in the payroll tax rate $\tau^{f}$, from $34 \%$ to $24 \%$. The impulse response functions of the main macroeconomic variables are thus reported in Figures 5, 6 and 7.

From Figure 5, panel (a), we can see that a given reduction in labor cost (through a fall in $\tau^{f}$ ) requires a less than proportional decrease in the consumption tax $\left(\tau^{c}\right)$. In period $1, \tau^{f}$ is indeed reduced from 0.34 to 0.24 . So as to offset the consequences of this tax cut on the government's budget constraint, the indirect tax rate is raised from 0.22 to 0.28 , while the employee's tax rate remains constant at 0.13 . The overall tax distortion therefore reduces, as $T W$ decreases from 1.88 to 1.825. This illustrates our tax base enlargement effect (Proposition 1).

As mentioned in the Introduction, one leading argument behind fiscal devaluation relates to its beneficial effects with regards to employment. As reported in Figure 5, panel (e), the employment level indeed increases following the optimal tax reform. The economic rationale is straightforward. The reduction in payroll taxes $\tau^{f}$ entices firms to increase labor input. On impact, the employment level $N$ being predetermined, this is achieved through an increase in worked hours $h$ (Figure 6, panel (a)). In parallel, firms start opening vacant jobs, so as to adjust at the extensive margin 
Figure 5: IRFs to the optimal tax reform (1)
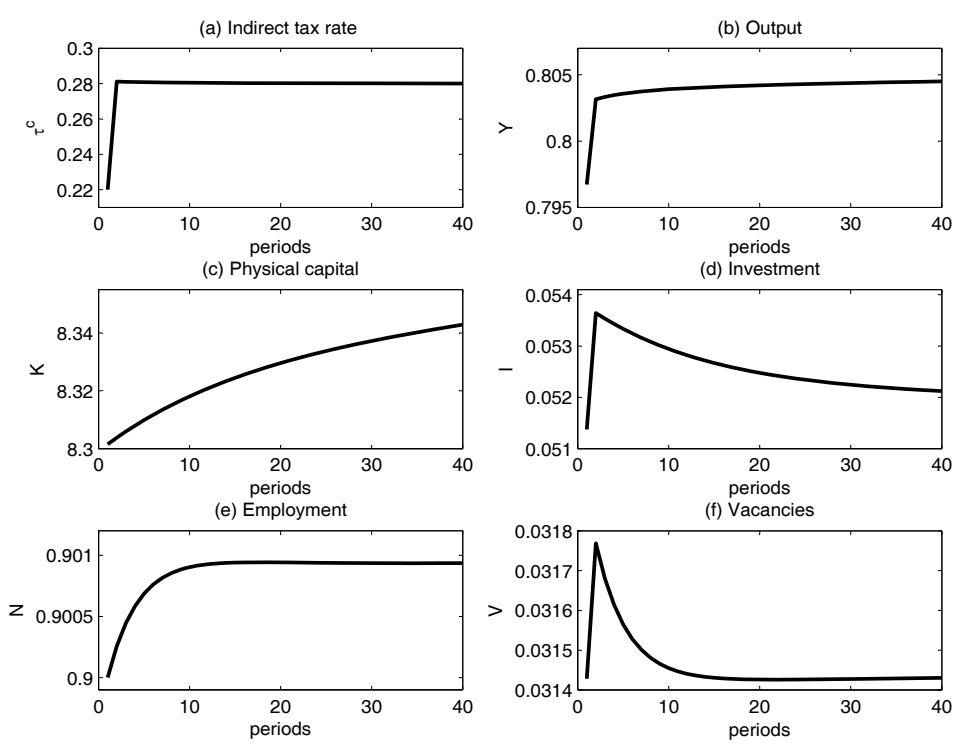

through the employment level the periods after the fiscal shock (Figure 5, panel (f)). As reported in Figure 5, panel (e), the employment level monotonically increases with the tax reform. In that respect, the tax reform reaches one of its assigned objective, ie the reduction in unemployment. The improvement of labor market conditions also entices unemployed workers to search more intensively: The effort level indeed increases with the tax reform, as reported in Figure 6, panel (b). Yet, our quantitative results indicate a modest gain in terms of employment: The tax reform indeed leads to a $0.1 \%$ increase in the employment level, which corresponds to a gain of around $+28,500$ employed workers. ${ }^{17}$ Most of the effects of the tax reform is channeled on labor input through the intensive margin adjustment: Worked hours therefore increase by $1 \%$.

The tax reform also leads to an increase in investment, hence in the capital stock (Figure 5, panels (c) and (d)). Firms are enticed to invest in physical capital as the marginal productivity of capital increases with the rise in worked hours and in employment. The rise in individual worked hours accounts for the immediate increase in production reported in Figure 5 (panel (b)). In subsequent periods onwards, the gradual increases in the employment level and the capital stock contribute to further raise output, which monotonically increases until reaching its new higher steady-state level. Again, the the effects are quantitatively modest, as the tax reform induces a 1\% increase in GDP.

Figure 6, panel (c) indicates that aggregate consumption increases with the tax reform. As in the walrasian setting, this can be understood as the result of two opposite effects: a negative relative

\footnotetext{
${ }^{17}$ This is based on the employed workforce in France, which amounts to 25,904 thousands of persons in 2008:1 (INSEE data).
} 
Figure 6: IRFs to the optimal tax reform (2)
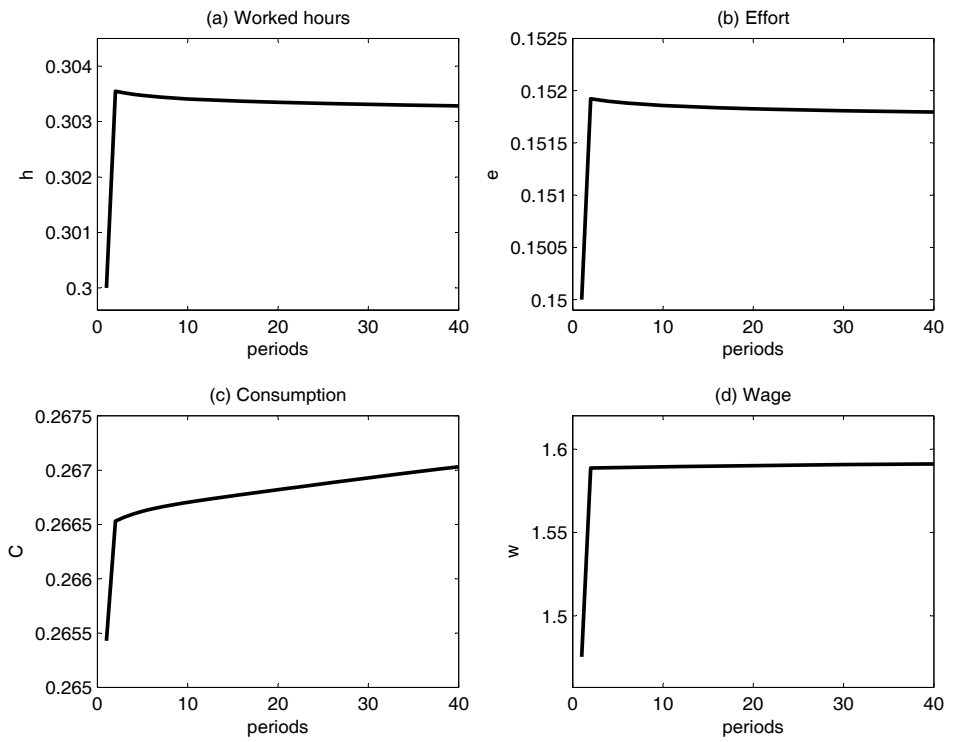

price effect inherent to the open-economy dimension (see the rise in the home CPI $P$, Figure 7, panel (b)), and a positive wealth effect, notably attributable to labor market adjustments. As reported in Figure 6 (panels (a) and (d)), both worked hours and the real wage increase with the tax reform. Households indeed accept to bargain an increase in worked hours $h$ as long it is accompanied by an increase in the real wage $w$. Despite the increase in the indirect tax rate, the magnitude of the wage increase makes the net real wage to increase, which contributes to the positive wealth effect of the tax reform. As reported in Figure 6, this dominating effect drives aggregate consumption upwards.

Next to employment, the other leading argument supporting the social VAT reform is the expected gains in terms of international trade. By altering the relative international prices in favor of the home firms, the reform is likely to improve their price-competitiveness, thereby boosting exports and the trade balance. In this respect, the expected effects are similar to that of an exchange rate devaluation. The open-economy implications of the tax reform are reported in Figure 7.

In line with these expected effects, Figure 7, panel (f) indeed shows that the trade balance becomes positive with the tax cut. More precisely (and similarly to the empirical effects of an exchange rate devaluation), the dynamics of the trade balance displays a "J-curve" following the optimal fiscal devaluation. On the one hand, the relative price of imported indeed goes up with the tax reform (panel (a)). The switch from direct to indirect taxation amounts taxing the imported varieties, which boosts domestic exports while reducing imports from abroad. As reported in Figure 7, panel (c), exports indeed go up. Everything else equal, this expenditure-switching effect tends to induce a trade balance surplus. On the other hand, due to the positive wealth effect, aggregate 
Figure 7: IRFs to the optimal tax reform (3)
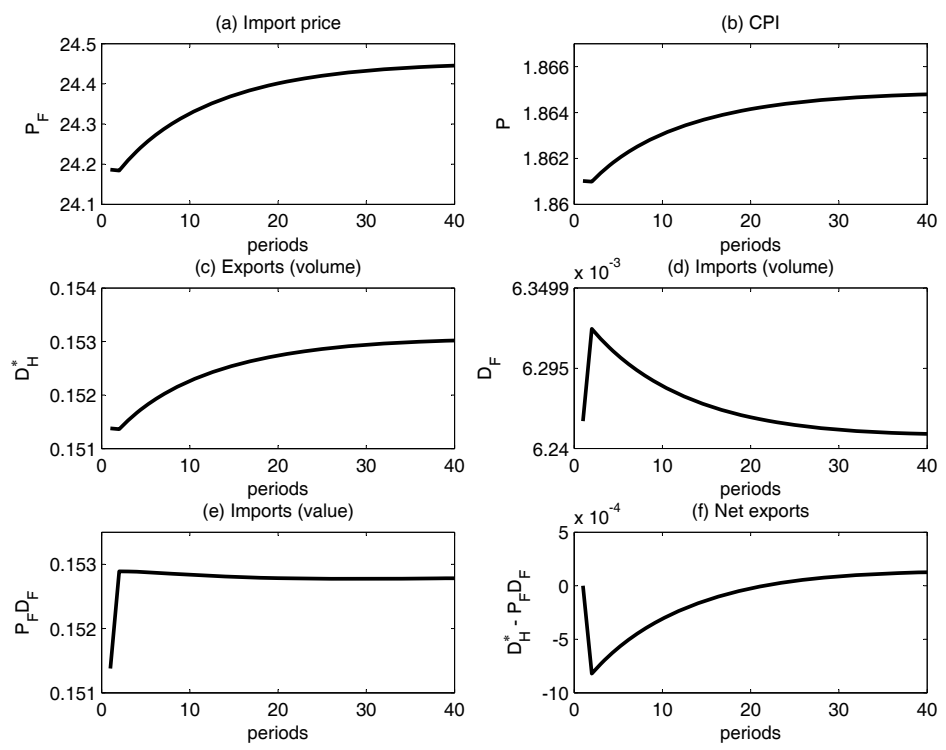

demand increases in the home economy. ${ }^{18}$ Everything else equal, this induces an increase in imports, hence a trade balance deficit. The trade balance dynamics is thus the result of both the expenditureshifting and the expenditure-switching effects. As displayed in Figure 7, the wealth effect on imports dominates in the short aftermath of the tax reform, as the trade balance becomes in deficit. The sustained price-competitiveness effect then induces a trade balance over the medium run.

\subsubsection{Sensitivity analysis}

In analyzing the effects of fiscal devaluation, we have put into evidence the key role of two dimensions: Labor market frictions and the open-economy dimension. In this section, we go deeper into this through a sensitivity analysis to both dimensions. Besides, the tax reform under focus here starts from a reduction in the employer's payroll tax rate. One may yet wonder about the effects of an alternative reform, that would rather consist in reducing the employee's labor tax rate. We also investigate this point here.

The role of labor market institutions Contrasting the welfare implication of the tax reform in the walrasian economy versus in the search economy has put into evidence the role of labor market frictions in shaping the optimal tax scheme. Precisely, the previous results suggest that they call for a larger magnitude of fiscal devaluation everything else equal. We now explore this point with more depth. Labor market institutions are summarized by two parameters in the model,

\footnotetext{
${ }^{18}$ Our previous results indeed indicate that all the components of the home demand increase with the tax reform.
} 
the unemployment benefit replacement rate $\rho$ and the firm's bargaining power $\epsilon$. Fiscal devaluation can reduce the inefficiency gap due to $\rho>0$ and $\epsilon \neq \psi$. We investigate each dimension alternatively.

Sensitivity to the unemployment benefit ratio In Figure 9, we report the welfare curve obtained when the open-search economy features a low unemployment benefit ratio: We retain $\rho=0.3$ (vs $\rho=0.56$ in the benchmark scenario), which corresponds to the values observed in the United-States and the United-Kingdom in the recent decades (1980-2003). ${ }^{19}$

Figure 8: Sensitivity to the unemployment benefit ratio

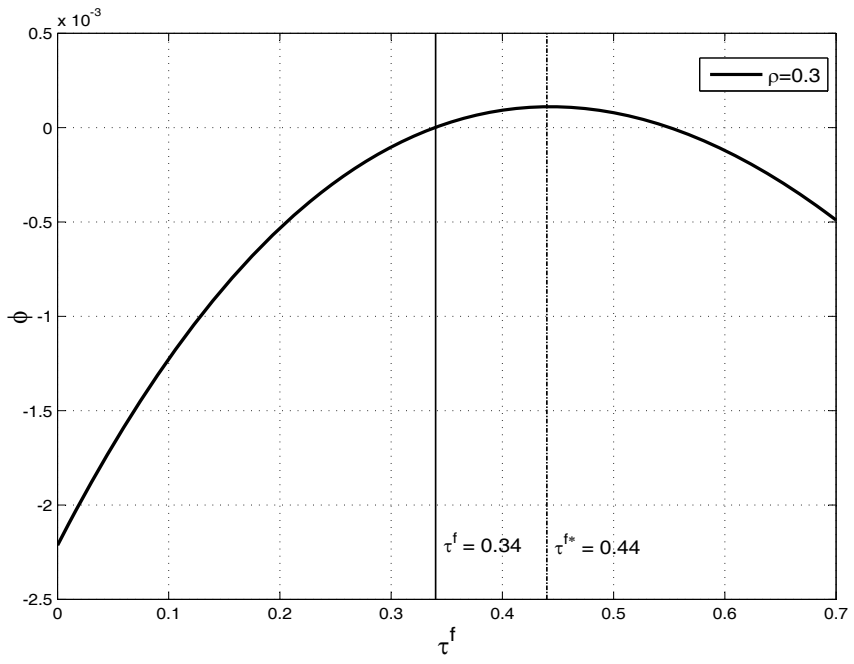

As reported in Figure 9, the optimal tax policy is reached for $\tau^{f *}=0.44$ (and $\tau^{c *}=0.14$ ). That is, the optimal tax reform consists in an "anti-fiscal" devaluation. This results stands in sharp contrast with the one obtained with a more generous unemployment benefit system $\left(\tau^{f *}=0.24\right.$ for $\rho=0.56$ ). This result can be accounted for by recalling the previous analytical insights (Section 4.1). The direct effect of the unemployment benefit is to increase labor costs which reduces the labor market tightness below its first-rank level (Equations (37) vs (38)), thus the search effort (Equations (39) vs (40))). This effect suggests that a large $\rho$ must be compensated by lower fiscal distortions, which is achieved by fiscal devaluation (Proposition 1). This stands in line with the results of Figure 4, obtained in the benchmark rigid labor market case $(\rho=0.56)$. The large labor market distortions induced by the strong generosity of the unemployment benefit system dominates the relative price effect, such as the optimal policy consists in reducing the payroll tax rate. By contrast, when unemployment benefits are low (Figure 9), the relative price effect inherent to the open-economy dimension dominates, by which the optimal tax policy is conversely an "anti-fiscal"

\footnotetext{
${ }^{19}$ This calibration is based on OECD data as provided in Nickell's (2006) CEP database.
} 
devaluation.

Sensitivity to the relative bargaining power The case where the firm's bargaining power $(\epsilon)$ differs from its contribution to the matching process $(\psi)$ constitutes another structural inefficiency that may be addressed by the tax policy. We now investigate this case. We thus derive the welfare curve associated to fiscal devaluation, in the scenario where $\epsilon<\psi$. Results are reported Figure ??

Figure 9: Optimal tax policy when $\epsilon<\psi$

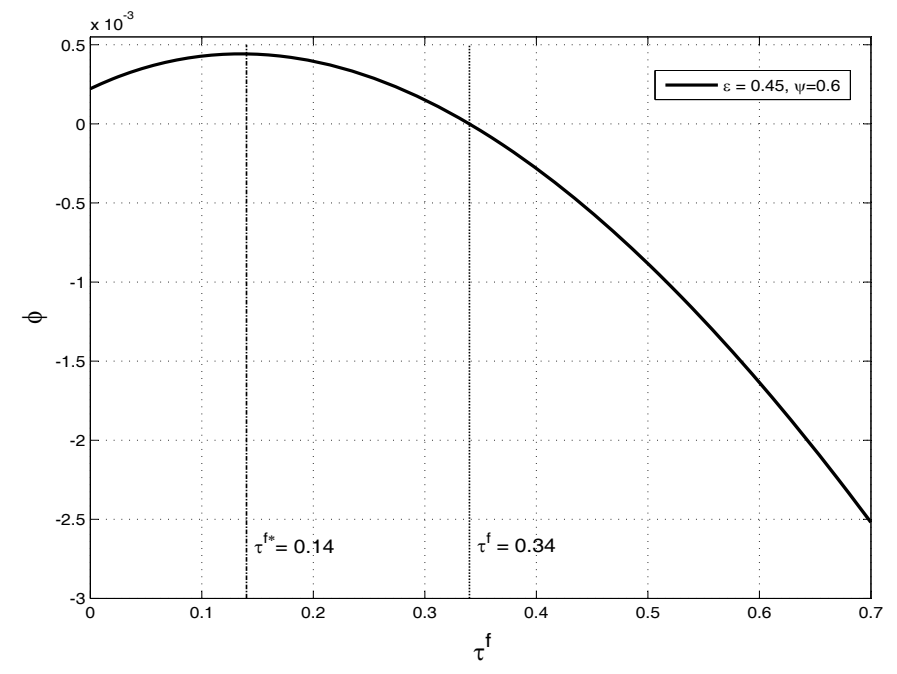

In the case $\epsilon<\psi$, the low share of the match rent attributed to firms (in comparison with their contribution to the match process) reduces their incentives to search for workers. As a related result, this lowers labor market tightness below its first-rank allocation (as can be inferred from the comparison between Equations (37) and (38)). The distortion induced by $\epsilon<\psi$ therefore implies as priority for the tax policy to increase firm's search effort by reducing the payroll tax rate (and reducing the consumption tax rate, but less than proportionally under Proposition 1). ${ }^{20}$ In the case $\{\epsilon=0.45, \psi=0.6\}$, the optimal tax policy is reached for $\tau^{f *}=0.14, \tau^{c *}=0.37$.

\footnotetext{
${ }^{20}$ It is worth noticing that the distortion $\epsilon<\psi$ may drive the optimal payroll tax rate downwards. Similarly as for firms, but running in the opposite direction, the too large bargaining power of workers induces too much search effort on their side (see Equations (39) and (40)). Everything else equal, the priority shall be to reduce incentive for unemployed worker to search for a job, which calls for a rise in fiscal distortions. In driving the optimal tax scheme though, the generosity of the unemployment benefits system also comes into play. The higher $\rho$, the less incentive to search for a job, in which case the optimal tax policy consists in a reduced payroll tax rate (ie, fiscal devaluation). In preliminary investigations, we check that for low but still empirically plausible values of the unemployment benefit ratio, the distortion $\epsilon<\psi$ still implies a lower tax burden.
} 
The role of the open-economy dimension Our overall results point out the important role of the open-economy dimension in the optimal tax design. Precisely, we have shown that the optimal tax scheme results of two opposite forces, labor market frictions and the competitiveness effect. Besides, it is also clear that transition matters, as put into evidence in the walrasian setting: Despite the promise of reaching a more efficient economy in the long run, the cost of transition pushes the welfare curve rightwards (Figures 2 vs 3 ). ${ }^{21}$

Pursuing along this line of reasoning, it is clear that fiscal devaluation will still be optimal only if the long-run promise is sufficiently large to compensate the costs of the transition. A sufficient condition is that the negative long run impact of the price effect remains small enough. The price effect is governed by the set of parameters determining the sensitivity of the trade balance to the foreign price $P_{F}$ (see Equation (41)). In particular, it is sensitive to the elasticity of substitution between home and foreign goods $\eta$. The intuition is straightforward. When goods are more substitutable (high $\eta$ ), any change in the foreign price induces larger consumption switching between home and foreign goods. Thus, a larger elasticity of substitution dampens the increase in the terms of trade that follows the tax reform, thereby isolating the home market from international fluctuations. In that case, the output gains of fiscal devaluation are only slightly dampened by the increase in the home CPI, its optimal tax rate being largely the result of the larger consumption tax base than the wage tax base. In other words, labor market inefficiencies play a dominant role, calling for a reduced labor cost. According to this reasoning, the higher $\eta$, the lower the optimal tax rate $\tau^{f \star}$, and the lower the tax wedge.

This drives us to characterize the optimal tax policy (with transition) when the economy exhibits a larger elasticity of substitution across national varieties. In Figure 10, we report the welfare curve obtained in the search economy with $\eta=1.5$, which corresponds to the value retained by Backus et al. (1995).

As displayed in Figure 10, the optimal tax policy is reached for null (even slightly negative) payroll tax rate $\left(\tau^{f *}=-0.01\right)$. The large part of the tax burden falls upon indirect taxation, with $\tau^{c *}=0.48$. Consistently with the previous reasoning, with a higher $\eta$, the hump-shape welfare curve shifts to the left (relative to Figure 4). A higher substitutability between home and foreign varieties implies a dampened relative price effect, which gives room for fiscal devaluation, all the more in presence of labor market distortions.

Reducing the payroll tax or the employee tax rate? As last investigation, we explore the role of the tax reform per se. Rather than reducing the payroll tax rate, fiscal devaluation may be

\footnotetext{
${ }^{21}$ In the search economy, the optimal tax policy in the long-run is reached for $\tau^{f \star}=-0.5$. The contrast between the optimal policy in the long run and with the transition dynamics included therefore drives the same interpretation as in the walrasian case. Accordingly, we choose to not report the long-run optimal tax reform in the presence of labor market frictions, for sake of brevity and conciseness. Results are of course available upon request to the authors.
} 
Figure 10: Sensitivity to the elasticity of substitution between goods

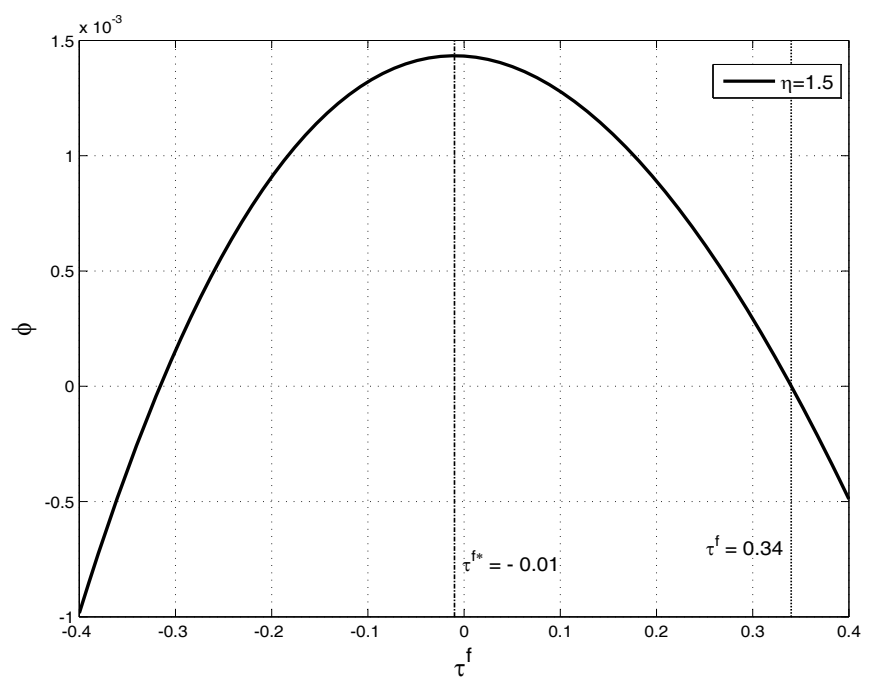

driven through a reduction in the employee's tax rate $\tau^{w}$. This drives us to evaluate the optimal tax design for such a tax reform, where the reduction in $\tau^{w}$ is offset by an adequate increase in $\tau^{c}$ so as to maintain welfare state programs (ie, the same ratios of public spending and transfers relative to output, as well as a constant payroll tax rate). Results are reported in Figure 11.

Figure 11: Alternative fiscal devaluation scheme (Reducing $\tau^{w}$ )

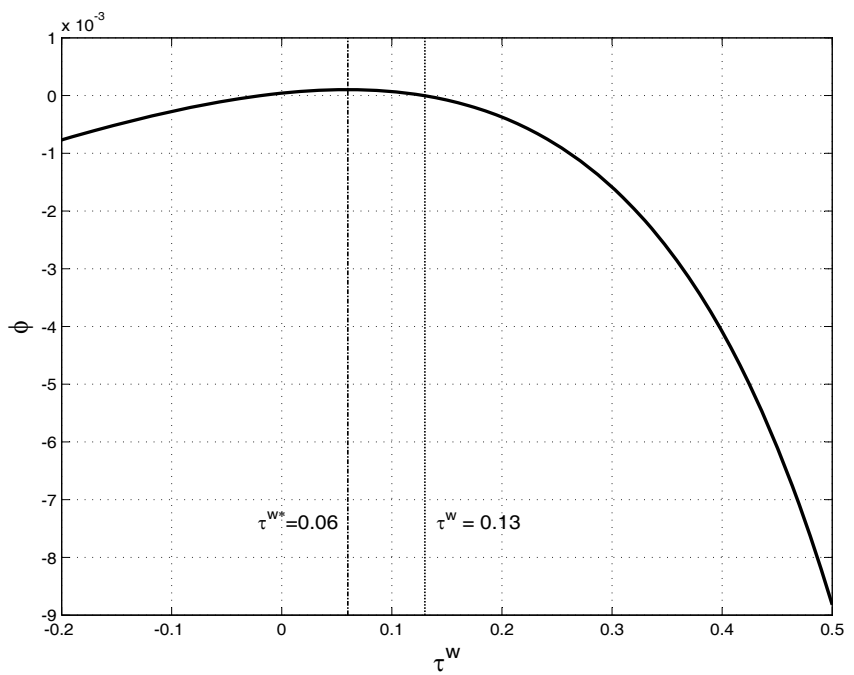

As displayed in Figure 11, and in line with our previous results, the welfare effect of the tax reform still displays a hump-shape behavior, with the peak of the hump-shaped welfare curve reached for $\tau^{w *}=0.06$, with a corresponding indirect tax rate $\tau^{c *}=0.28$. This confirms the robustness of the 
two key effects of fiscal devaluation that we have put into evidence. One the one hand, labor market frictions call for a reduced labor tax, while the competitive price effect, by dampening the agents' purchasing power, conversely shifts the welfare curve rightwards. As shown by Figure 11, these two effects remain at the heart of the optimal tax reform, whether it is conducted through a reduction in $\tau^{w}$ or $\tau^{f}$. It is indeed noticeable that the optimal tax reform is reached for an identical value of the tax wedge $T W$ (equal to 1.825). The result, that the modality of the tax reform (whether reducing $\tau^{f}$ or $\tau^{w}$ ) is somehow not surprising in light of the model's equations. As exemplified in the negotiated wage and hours contract (Equations (20) or (19)) or the optimal search effort equation $(21)$, it is the ratio $\left(1+\tau^{f}\right) /\left(1-\tau^{w}\right)$ that intervenes, and as it can be contemplated in steady-state, the overall tax distortion $\left(T W=\left(\left(1+\tau^{c}\right)\left(1+\tau^{f}\right)\right) /\left(1-\tau^{w}\right)\right) \cdot{ }^{22,23}$ In our framework then, whether the reduction in labor taxation operates either through the employee's or the employer's side does not make a substantial difference. In both cases, the optimal tax scheme can be understood as the result of two opposite forces, labor market distortions and the open-economy relative price effect.

\section{Conclusion}

This paper studies fiscal devaluation in a small-open economy search model. We evaluate the effectiveness of the tax reform relying on both analytical results and quantitative simulations. We put into evidence the analytical conditions under which the tax reform can be welfare-improving in the long run. First, we show that the key condition under which there is scope for fiscal devaluation relates to a tax base comparison. It should indeed be the case that the consumption tax base is larger than the payroll tax base. Under this condition, we show that fiscal devaluation is always welfare-enhancing in a closed walrasian setting. Second, the adding of the open-economy dimension and of labor market frictions makes things less trivial. Interestingly, our results indicate that both dimensions have an opposite effect on welfare. Fiscal devaluation is welfare-improving as it tends to dampen the effect of labor inefficiencies (thereby lowering the gap with the Hosios allocation). The more stringent labor market institutions, the larger magnitude of the labor tax cut. By contrast, by raising the relative price of imports, fiscal devaluation induces a relative price effect, which exerts a downward pressure on the home agents' purchasing power. This, in turn, tends to reduce welfare by dampening the beneficial effects of the fiscal reform on output and consumption. The extent of the relative price effect crucially depends on the trade balance adjustment. In particular, the less substituability between domestic and foreign varieties, the higher the increase in the relative imports price and in the home CPI. These contrasting effects give rise to an optimal tax scheme. Last, our results put into evidence that the transitional cost of the tax reform are not negligible.

\footnotetext{
${ }^{22}$ See Section A.4.

${ }^{23}$ As previously mentioned, an important element in driving the equivalence of results between reducing $\tau^{w}$ or $\tau^{f}$ is the assumption that both labor revenues and unemployment benefits are taxed at the same rate.
} 
Fiscal devaluation can only be optimal if the negative long-run impact of the price effect remains small enough, allowing the agents to endure the short-run costs of the reform. Everything else equal, this calls for a limited magnitude of fiscal devaluation.

We provide a quantitative assessment of the optimal tax reform, using France as benchmark economy. We thus show that there is room for fiscal devaluation, as our model predicts an optimal payroll tax rate of $24 \%$ (versus $34 \%$ in the benchmark (current) situation). We characterize the positive implications of this reform. In line with the supporters of the reform, employment increases with the tax reform, as well as most macroeconomic aggregates (output, consumption, investment). As well, the reform drives a trade balance surplus for some periods after the fiscal change. Yet, in the immediate aftermath of the reform, the boost in imports dominates, leading to a trade balance deficit. Similarly as for a traditional exchange rate devaluation, the fiscal reform induces a "J-curve" trade balance pattern. Besides, if employment increases, the quantitative effects are modest $(+0.1 \%$ of the employment level, corresponding to a gain of $+28,500$ workers in France).

Our results are derived under the assumption of perfect competition. Future work shall extend our results to the case of monopolistic competition in order to get a more subtle message on price behavior. In addition, we somehow understate the inefficiency associated with the open-economy dimension as we preclude in the paper any permanent change in external balance. One might also wonder about the fiscal policy response from the foreign country to the change in tax scheme in the home country. All elements are interesting questions that are left for future research.

\section{References}

Adao, B., Correia, I. \& Teles, P. (2009), 'On the relevance of exchange rate regimes for stabilization policy', Journal of Economic Theory 144(4), 1468-1488.

Albertini, J. \& Fairise, X. (2009), Optimal unemployment benefit financing scheme: A transatlantic comparison, EPEE Working Paper 09-01, EPEE.

Andolfatto, D. (1996), 'Business cycles and labor-market search', The American Economic Review (1), 112-132.

Backus, D., Kehoe, P. \& Kydland, F. (1995), International real business cycles: Theory versus evidence, in T. Cooley, ed., 'Frontiers of Business Cycle Research', Princeton University Press, pp. 213-231.

Blanchard, O. \& Wolfers, J. (2000), 'The role of shocks and institutions in the rise of european unemployment: The aggregate evidence', Economic Journal 110. 
Chéron, A. \& Langot, F. (2004), 'Labor market search and real business cycles: reconciling nash bargaining with the real wage dynamics', Review of Economic Dynamics pp. 476-493.

Corsetti, G. \& Pesenti, P. (2001), 'Welfare and Macroeconomic Interdependence', The Quarterly Journal of Economics 116(2), 421-445.

Cotis, J.-P. (2009), Partage de la valeur ajoutée, partage des profits et écarts de rémunérations en France, Report, INSEE.

Diamond, P. (1982), 'Wage determination and efficiency in search equilibrium', Review of Economic Studies pp. 217-227.

Farhi, E., Gopinath, G. \& Itskhoki, O. (2011), Fiscal devaluations, NBER Working paper 17662, NBER.

Hairault, J.-O. (2002), 'Labor-market search and international business cycles', Review of Economic Dynamics 5, 535-558.

Hairault, J.-O., LeBarbanchon, T. \& Sopraseuth, T. (2011), The ins and outs of french unemployment, Mimeo, french version with y. dubois, dares 2011-167, decembre 2011, PSE.

IMF (2011), Fiscal Monitor: Addressing Fiscal Challenges to Reduce Economic Risks, IMF, Washington D.C.

Kollmann, R. (2001), 'Explaining international comovement of output and asset returns: The role of money and nominal rigidities', Journal of Economic Dynamics and Control 25, 1547-1583.

Kollmann, R. (2002), 'Monetary policy rules in the open economy: Effects on welfare and business cycles', Journal of Monetary Economics 49, 989-1015.

Krause, M. \& Lubik, T. A. (2007), 'The (ir)relevance of real wage rigidity in the new keynesian model with search frictions', Journal of Monetary Economics 54(4), 706-727.

Landais, C., Piketty, T. \& Saez, E. (2011), Pour une révolution fiscale - Un impôt sur le revenu pour le $21^{e}$ siècle, Seuil, Paris.

Lane, P. \& Milesi-Ferretti, G. (2001), 'Long-term capital movements', NBER Macroeconomics Annual 16, 73-116.

Langot, F. (1995), Unemployment and real business cycle : A matching model, in P. Hénin, ed., 'Advances in Economic Business Cycles Theory', Springer Verlag, chapter 8. 
Langot, F. (1996), 'A-t-on besoin d'un modèle d'hystérèse pour rendre compte de la persistance du chômage?', Annales d'Economie et de Statistique 44, 29-57.

Le Barbanchon, T., Ourliac, B. \& Simon, O. (2011), Les marchés du travail français et américain face aux chocs conjoncturels des années 1986 à 2007 : une modélisation dsge, INSEE Document de Travail G 2011 / 01, INSEE.

Lucas, R. (1987), Models of Business Cycles, Blackwell, Oxford.

Lucas, R. E. (2003), 'Macroeconomic priorities', American Economic Review 93(1), 1-14.

Mortensen, D. (1982), The matching process as a non-cooperative/bargaining game, in J. Mccall, ed., 'The Economics of Information and Uncertainty', NBER Conference Volume.

Nickell, W. (2006), The cep - oecd institutions dataset (1960-2004), Discussion Paper 0759, Centre for Economic Performance.

Ohanian, L., Raffo, A. \& Rogerson, R. (2008), 'Long-term changes in labor supply and taxes: Evidence from oecd countries, 1956-2004', Journal of Monetary Economics 55(8), 1353-1362.

Patureau, L. (2007), 'Pricing-to-market, limited participation and exchange rate dynamics', Journal of Economic, Dynamics and Control 31, 3281-3320.

Pissarides, C. (1985), 'Short-run equilibrium dynamics of unemployment, vacancies and real wages', American Economic Review 75, 676-90.

Pissarides, C. (1990), Equilibrium Unemployment Theory, Basil Blackwell, Oxford.

Prescott, E. (2004), 'Why do Americans work so much more than Europeans?', Federal Reserve Bank Of Minneapolis Quarterly Review.

Rogerson, R. (2006), 'Understanding Differences in Hours Worked', Review of Economic Dynamics 9(3), 365-409.

Shimer, R. (2009), 'Convergence in macroeconomics: The labor wedge', American Economic Journal: Macroeconomics 1, 280-297.

\section{A Search model}

\section{A.1 The household's program}

The dynamic problem of a typical household can be written as follows:

$$
\mathcal{W}^{H}\left(\Omega_{t}^{H}\right)=\max _{C_{t}^{n}, C_{t}^{u}, B_{t+1}}\left\{N_{t} U\left(C_{t}^{n}, h_{t}\right)+\left(1-N_{t}\right) U\left(C_{t}^{u}, e_{t}\right)+\beta \mathcal{W}^{H}\left(\Omega_{t+1}^{H}\right)\right\}
$$


subject to the set of constraints:

$$
\begin{aligned}
N_{t+1} & =(1-s) N_{t}+e_{t} p_{t}\left(1-N_{t}\right) \\
P_{t} B_{t+1} & +P_{t}\left(1+\tau_{t}^{c}\right)\left[N_{t} C_{t}^{n}+\left(1-N_{t}\right) C_{t}^{u}\right] \\
& \leq P_{H t}\left(1-\tau_{t}^{w}\right) w_{t} h_{t} N_{t}+\left(1-N_{t}\right) P_{H t}\left(1-\tau_{t}^{w}\right) b_{t}+P_{t} B_{t}\left(1+i_{t}^{F}\right)+T_{t}+\pi_{t}
\end{aligned}
$$

and given some initial conditions $\left(N_{0}, K_{0}\right)$. With $\lambda_{t}$ the shadow price of the budget constraint, the first order conditions with respect to consumption and international bonds are respectively given by Equations (eq:FOCc) and (8). As indicated by Equation (7), $C_{t}^{n}=C_{t}^{u}=C_{t}$.

\section{A.2 Nash bargaining on the labor market}

Wage and hours contracts are solutions of maximizing the match surplus according to:

$$
\max _{w_{t}, h_{t}}\left(\lambda_{t} \mathcal{V}_{t}^{F}\right)^{\epsilon}\left(\mathcal{V}_{t}^{H}\right)^{1-\epsilon}
$$

Given the firm's value function $\mathcal{W}_{t}^{F}$, the marginal value of a match $\mathcal{V}_{t}^{F}=\frac{\partial \mathcal{W}_{t}^{F}}{\partial N_{t}}$ is equal to:

$$
\mathcal{V}_{t}^{F}=P_{H t} F_{N h t}^{\prime} h_{t}-P_{H t} w_{t} h_{t}\left(1+\tau_{t}^{f}\right)+(1-s) \beta\left[\frac{\lambda_{t+1}}{\lambda_{t}} \mathcal{V}_{t+1}^{F}\right]
$$

where $F_{N h t}^{\prime}$ stands for the marginal product of labor input and $F_{N h t}^{\prime} h_{t}$ is the output for a person that works $h_{t}$ hours.

The marginal value of the match for the household is defined as $\mathcal{V}_{t}^{H}=\Psi_{t}^{n}-\Psi_{t}^{u}$, where $\Psi_{t}^{n}$ and $\Psi_{t}^{n}$ represent the marginal values of being employed and unemployed respectively. As in Langot (1995), these values are defined as $\Psi_{t}^{n} \equiv \frac{\partial \mathcal{W}_{t}^{H}}{\partial N_{t}}$ and $\Psi_{t}^{u} \equiv \frac{\partial \mathcal{W}_{t}^{H}}{\partial U_{t}}=\frac{\partial \mathcal{W}_{t}^{H}}{\partial N_{t}} \frac{\partial N_{t}}{\partial U_{t}}=-\frac{\partial \mathcal{W}_{t}^{H}}{\partial N_{t}}$, with $U_{t}=1-N_{t}$ the unemployment state variable and $\mathcal{W}_{t}^{H}$ the value function of the household according to Equation (42). Alternatively, $\Psi_{t}^{u}$ can be interpreted as the threat point of the worker in the Nash bargaining.

Before deriving the expressions for $\Psi_{t}^{n}$ and $\Psi_{t}^{u}$, it is convenient to rewrite the household's problem as a function of the two state variables $N_{t}, U_{t}$ summarizing the worker's employment status:

$$
\mathcal{W}^{H}\left(N_{t}, U_{t}, B_{t}\right)=\max _{C_{t}, B_{t+1}}\left\{\log C_{t}+N_{t} \Gamma_{t}^{n}+U_{t} \Gamma_{t}^{u}+\beta \mathcal{W}^{H}\left(N_{t+1}, U_{t+1}, B_{t+1}\right)\right\}
$$

subject to the set of constraints:

$$
\begin{aligned}
N_{t+1} & =(1-s) N_{t}+e_{t} p_{t} U_{t} \\
U_{t+1} & =\left(1-e_{t} p_{t}\right) U_{t}+s N_{t} \\
\left(1+\tau_{t}^{c}\right) P_{t} C_{t}+P_{t} B_{t+1} & =\left(1-\tau_{t}^{w}\right) P_{H t} w_{t} h_{t} N_{t}+\left(1-\tau_{t}^{w}\right) P_{H t} b_{t} U_{t}+P_{t} B_{t}\left(1+i_{t}^{F}\right)+T_{t}+\pi_{t}
\end{aligned}
$$


With $\lambda_{t}$ the shadow price of the budget constraint, we thus obtain the following expressions for $\Psi_{t}^{n}$ and $\Psi_{t}^{u}$ :

$$
\begin{aligned}
\Psi_{t}^{n} & =P_{H t}\left(1-\tau_{t}^{w}\right) \lambda_{t} w_{t} h_{t}+\Gamma_{t}^{n}+\beta\left[(1-s) \Psi_{t+1}^{n}+s \Psi_{t+1}^{u}\right] \\
\Psi_{t}^{u} & =P_{H t}\left(1-\tau_{t}^{w}\right) b_{t} \lambda_{t}+\Gamma_{t}^{u}+\beta\left[e_{t} p_{t} \Psi_{t+1}^{n}+\left(1-e_{t} p_{t}\right) \Psi_{t+1}^{u}\right]
\end{aligned}
$$

From the above equations and the definition for $\mathcal{V}_{t}^{H}$ as $\frac{\partial \mathcal{W}_{t}^{H}}{\partial N_{t}} \equiv \mathcal{V}_{t}^{H}=\Psi_{t}^{n}-\Psi_{t}^{u}$, we get that the marginal value of a match for the household is given by:

$$
\mathcal{V}_{t}^{H}=\Gamma_{t}^{n}-\Gamma_{t}^{u}+P_{H t} \lambda_{t}\left(1-\tau_{t}^{w}\right)\left[w_{t} h_{t}-b_{t}\right]+\left(1-s-e_{t} p_{t}\right) \beta \mathcal{V}_{t+1}^{H}
$$

Given the marginal values of a match for a firm and a worker as expressed by Equations (46) and (48), maximizing the match surplus (45) with respect to $w_{t}$ and $h_{t}$ delivers the set of first-order conditions:

$$
\begin{aligned}
\frac{\epsilon}{\mathcal{V}_{t}^{F}} \frac{\partial \mathcal{V}_{t}^{F}}{\partial h_{t}} & +\frac{1-\epsilon}{\mathcal{V}_{t}^{H} \frac{\partial \mathcal{V}_{t}^{H}}{\partial h_{t}}=0} \\
\underbrace{\frac{\epsilon}{\lambda_{t}} \mathcal{V}_{t}^{H}}_{L H S} & =\underbrace{(1-\epsilon) \frac{1-\tau_{t}^{w}}{1+\tau_{t}^{f}} \mathcal{V}_{t}^{F}}_{R H S}
\end{aligned}
$$

Negotiation on worked hours Making use of Equation (50), the first-order condition on worked hours (49) can be rewritten as:

$$
\lambda_{t} \frac{1-\tau_{t}^{w}}{1+\tau_{t}^{f}} \frac{\partial \mathcal{V}_{t}^{F}}{\partial h_{t}}+\frac{\partial \mathcal{V}_{t}^{H}}{\partial h_{t}}=0
$$

Besides, from Equations (46) and (48), we get that:

$$
\begin{aligned}
\frac{\partial \mathcal{V}_{t}^{F}}{\partial h_{t}} & =P_{H t} F_{N h t}^{\prime}-P_{H t} w_{t}\left(1+\tau_{t}^{f}\right) \\
\frac{\partial \mathcal{V}_{t}^{H}}{\partial h_{t}} & =\left(1-\tau_{t}^{w}\right) P_{H t} w_{t} \lambda_{t}-\sigma_{n} h_{t}^{\eta_{L}}
\end{aligned}
$$

Replacing (52) and (53) into (51) and dividing by $P_{t} \lambda_{t}$ yields Equation (19) as solution for the negotiated amount of worked hours.

Wage contract Using Equations (48) and (50), the left-hand side of Equation (50) yields:

$$
L H S \equiv \frac{\epsilon}{\lambda_{t}} \mathcal{V}_{t}^{H}=\frac{\epsilon}{\lambda_{t}}\left[\begin{array}{c}
\Gamma_{t}^{n}-\Gamma_{t}^{u}+P_{H t} \lambda_{t}\left(1-\tau_{t}^{w}\right)\left[w_{t} h_{t}-b_{t}\right] \\
+\left(1-s-e_{t} p_{t}\right) \beta\left[\frac{1-\epsilon}{\epsilon} \frac{1-\tau_{t+1}^{w}}{1+\tau_{t+1}^{f}} \lambda_{t+1} \mathcal{V}_{t+1}^{F}\right.
\end{array}\right]
$$

Besides, using Equation (46) allows to rewrite the RHS of Equation (50) as :

$$
R H S \equiv(1-\epsilon)\left(\frac{1-\tau_{t}^{w}}{1+\tau_{t}^{f}}\right) \mathcal{V}_{t}^{F}=(1-\epsilon)\left(\frac{1-\tau_{t}^{w}}{1+\tau_{t}^{f}}\right)\left[\begin{array}{c}
P_{H t} F_{N h t}^{\prime} h_{t}-P_{H t} w_{t} h_{t}\left(1+\tau_{t}^{f}\right) \\
+(1-s) \beta\left[\frac{\lambda_{t+1}}{\lambda_{t}} \mathcal{V}_{t+1}^{F}\right]
\end{array}\right]
$$


Equating Equations (54) and (55) in accordance with Equation (50) and dividing by $P_{t}\left(1-\tau_{t}^{w}\right)$ finally delivers the wage contract equation (20).

Optimal search effort The optimal search effort is obtained as the solution for maximizing the threat point $\Psi_{t}^{u}$ :

$$
\frac{\partial \Psi_{t}^{u}}{\partial e_{t}}=0 \Rightarrow-\frac{\partial \Gamma_{t}^{u}}{\partial e_{t}}=e_{t} p_{t} \beta \mathcal{V}_{t+1}^{H}
$$

Using Equation (50) to replace $\mathcal{V}_{t+1}^{H}$ by $\mathcal{V}_{t+1}^{F}$, we get

$$
-\frac{\partial \Gamma_{t}^{u}}{\partial e_{t}}=\frac{1-\epsilon}{\epsilon} e_{t} p_{t} \beta\left[\frac{1-\tau_{t+1}^{w}}{1+\tau_{t+1}^{f}} \mathcal{V}_{t+1}^{H}\right]
$$

Besides, the firm's first-order condition with respect to employment (that yields Equation (16) in the paper) is given by:

$$
\frac{P_{t} \bar{\omega}}{q_{t}}=\beta\left[\frac{\lambda_{t+1}}{\lambda_{t}} \mathcal{V}_{t+1}^{F}\right]
$$

Using this in Equation (56), as well as the definition of $\Gamma_{t}^{u}$, yields the optimal search effort (21).

\section{A.3 Summarizing the model}

Assuming that unemployment benefits are proportional to the wage according to: $b_{t}=\rho w_{t} h_{t}$, with $0<\rho<1$ the unemployment benefit ratio, and given the price normalization $\left(P_{H}=1\right)$, the search 
model can be summarized by the following set of equations:

$$
\begin{aligned}
& K_{t+1}=(1-\delta) K_{t}+I_{t} \\
& N_{t+1}=(1-s) N_{t}+M_{t} \\
& B_{t+1}=\left(1+i_{t}^{F}\right) B_{t}+\frac{Y_{t}}{P_{t}}-D_{t} \\
& P_{t} G_{t}=\bar{g} Y_{t} \\
& P_{t} G_{t}+P_{t} T_{t}=\tau_{t}^{c} P_{t} C_{t}+\left(\tau_{t}^{f}+\tau_{t}^{w}\right) N_{t} w_{t} h_{t}-\left(1-\tau_{t}^{w}\right) \rho w_{t} h_{t}\left(1-N_{t}\right) \\
& P_{t} T_{t}=\bar{t} Y_{t} \\
& q_{t}^{k}=1+\phi_{K} \frac{I_{t}-\delta K_{t}}{K_{t}} \\
& \theta_{t}=\frac{V_{t}}{e_{t}\left(1-N_{t}\right)} \\
& q_{t}=\chi \theta_{t}^{\psi-1} \\
& p_{t}=\frac{M_{t}}{e_{t}\left(1-N_{t}\right)} \\
& Y_{t}=A K_{t}^{\alpha}\left(N_{t} h_{t}\right)^{1-\alpha} \\
& M_{t}=\chi V_{t}^{\psi}\left[e_{t}\left(1-N_{t}\right)\right]^{1-\psi} \\
& \Gamma_{t}^{n}=-\sigma_{n} \frac{h_{t}^{1+\eta_{L}}}{1+\eta_{L}} \\
& \Gamma_{t}^{u}=-\sigma_{u} \frac{e_{t}^{1+\eta_{L}}}{1+\eta_{L}} \\
& Y_{t}=\xi P_{t}^{\eta} D_{t}+\left(1-\xi^{*}\right)\left(P_{t}^{*}\right)^{\eta^{*}} Y^{*} \\
& D_{t}=C_{t}+I_{t}+\bar{\omega} V_{t}+\frac{\phi_{K}}{2} \frac{\left(I_{t}-\delta K_{t}\right)^{2}}{K_{t}}+G_{t} \\
& P_{t}=\left[\xi+(1-\xi) P_{F t}^{1-\eta}\right]^{\frac{1}{1-\eta}} \\
& P_{t}^{*}=\left[\xi^{*} P_{F t}^{1-\eta^{*}}+\left(1-\xi^{*}\right)\right]^{\frac{1}{1-\eta^{*}}} \\
& D_{F t}=(1-\xi)\left(\frac{P_{F t}}{P_{t}}\right)^{-\eta} D_{t} \\
& S C_{t}=\bar{\omega}\left[\frac{1-s}{q_{t}}\left(1-\frac{1+\tau_{t}^{f}}{1+\tau_{t+1}^{f}} \frac{1-\tau_{t+1}^{w}}{1-\tau_{t}^{w}}\right)+e_{t} \theta_{t}\left(\frac{1+\tau_{t}^{f}}{1+\tau_{t+1}^{f}} \frac{1-\tau_{t+1}^{w}}{1-\tau_{t}^{w}}\right)\right] \\
& B S_{t}=\frac{1}{P_{t}}(1-\alpha) \frac{Y_{t}}{N_{t}}+S C_{t}
\end{aligned}
$$




$$
\begin{aligned}
\frac{1}{C_{t}} & =\left(1+\tau_{t}^{c}\right) P_{t} \lambda_{t} \\
\sigma_{n} h_{t}^{1+\eta_{L}} & =\frac{1-\tau_{t}^{w}}{\left(1+\tau_{t}^{c}\right)\left(1+\tau_{t}^{f}\right)}(1-\alpha) \frac{Y_{t}}{N_{t}} \frac{1}{P_{t} C_{t}} \\
\sigma_{u} e_{t}^{1+\eta_{L}} & =\frac{1-\tau_{t}^{w}}{\left(1+\tau_{t}^{c}\right)\left(1+\tau_{t}^{f}\right)} \frac{1-\epsilon}{\epsilon} e_{t} \theta_{t} \frac{1}{C_{t}} \\
w_{t} h_{t} & =\frac{1-\epsilon}{1+\tau_{t}^{f}} P_{t} B S_{t}+\epsilon\left[\rho w_{t} h_{t}+\frac{\Gamma_{t}^{u}-\Gamma_{t}^{n}}{\left(1-\tau_{t}^{w}\right) \lambda_{t}}\right] \\
1+i_{t}^{F} & =1+i^{*}-\phi_{B} \frac{P_{t} B_{t}}{Y_{t}} \\
\bar{\omega} & =\beta\left[\frac{P_{t+1} \lambda_{t+1}}{P_{t} \lambda_{t}}\left\{\frac{1}{P_{t+1}}(1-\alpha) \frac{Y_{t+1}}{N_{t+1}}+(1-s) \frac{\bar{\omega}}{q_{t+1}}-\left(1+\tau_{t+1}^{f}\right) w_{t+1} h_{t+1}\right\}\right] \\
q_{t}^{k} & =\beta\left[\frac{P_{t+1} \lambda_{t+1}}{P_{t} \lambda_{t}}\left\{\frac{1}{P_{t+1}} \alpha \frac{Y_{t+1}}{K_{t+1}}+q_{t+1}^{k}-\delta+\frac{\phi_{K}}{2}\left(\frac{I_{t+1}-\delta K_{t+1}}{K_{t+1}}\right)^{2}\right\}\right] \\
1 & =\beta\left[\frac{P_{t+1} \lambda_{t+1}}{P_{t} \lambda_{t}}\left\{1+i_{t+1}^{*}-\phi_{b} \frac{P_{t+1} B_{t+1}}{Y_{t+1}}\right\}\right]
\end{aligned}
$$

Note that $S C$ refers to search costs, and $B S$ to the bargained surplus. In accordance with the small-open economy assumption, the foreign interest rate $i^{*}$ and the foreign aggregate demand term $Y^{*}$ are considered as exogenous, and assumed to be constant. The transition dynamics is computed using Dynare. 


\section{A.4 The search model in steady-state}

The list of equations In steady-state, and under the assumption of a null trade balance (ie, $B=0$ ), the previous set of equations simplifies to the system of 15 equations:

$$
\begin{aligned}
& \left(1-\xi^{*}\right)\left[\xi^{*} P_{F}^{1-\eta^{*}}+\left(1-\xi^{*}\right)\right]^{\frac{1}{1-\eta^{*}}} Y^{*}=\frac{(1-\xi) P_{F}^{1-\eta}}{\xi+(1-\xi) P_{F}^{1-\eta}} Y \\
& \frac{P \bar{\omega}}{\chi} \theta^{1-\psi}=\frac{\beta}{1-\beta(1-s)} \frac{Y}{N}\left[(1-\alpha)-\left(1+\tau^{f}\right) \frac{w h N}{Y}\right] \\
& \sigma_{n} h^{1+\eta_{L}}=\frac{1-\tau^{w}}{\left(1+\tau^{f}\right)\left(1+\tau^{c}\right)} \frac{1-\alpha}{N}\left[\frac{1}{P C / Y}\right] \\
& \sigma_{u} e^{1+\eta_{L}}=\frac{1-\tau^{w}}{\left(1+\tau^{c}\right)\left(1+\tau^{f}\right)} \frac{1-\epsilon}{\epsilon \omega e \theta} \frac{1}{Y}\left[\frac{1}{P C / Y}\right] \\
& k=\left[\frac{\alpha \beta}{1-\beta(1-\delta)}\right]^{\frac{1}{1-\alpha}} A^{\frac{1}{1-\alpha}} P^{\frac{-1}{1-\alpha}} \\
& P=\left[\xi+(1-\xi) P_{F}^{1-\eta}\right]^{\frac{1}{1-\eta}} \\
& \bar{g}=\tau^{c}(P C / Y)+\left(\tau^{f}+\tau^{w}\right) \frac{w h N}{Y}-\left(1-\tau^{w}\right) \rho \frac{w h(1-N)}{Y}-\bar{t} \\
& Y=A k^{\alpha} N h \\
& \frac{w h N}{Y}=\frac{\eta_{L}(1-\epsilon) \frac{P \bar{\omega} e \theta N}{Y}+\left[1+\eta_{L}(1-\epsilon)\right](1-\alpha)}{\left(1+\tau^{f}\right)\left(1+\eta_{L}\right)(1-\rho \epsilon)} \\
& s N=e p(\theta)(1-N) \\
& p(\theta)=\theta q(\theta) \\
& q(\theta)=\chi \theta^{\psi-1} \\
& 1=\frac{P C}{Y}+\frac{P I}{Y}+\frac{P \bar{\omega} V}{Y}+\bar{g} \\
& \frac{P I}{Y}=\frac{\alpha \beta \delta}{1-\beta(1-\delta)} \\
& V=\theta e(1-N) \\
& \hline
\end{aligned}
$$

with $k \equiv \frac{K}{N h}, \bar{g} \equiv \frac{P G}{Y}$ and $\bar{t} \equiv \frac{P T}{Y}$.

Obtaining the steady-state labor market tightness We detail here some calculus to obtain steady-state results. To obtain the steady-state labor market tightness, we start combining the firm's labor demand $((S 2))$ with the wage contract equation $(S 9)$. From Equation $(S 2)$, labor demand can be rewritten as:

$$
\frac{P \bar{\omega} \theta^{1-\psi}}{\chi}=\frac{\beta}{1-\beta(1-s)} \Pi
$$


with $\Pi$ defined as:

$$
\Pi \equiv(1-\alpha) \frac{Y}{N}-\left(1+\tau^{f}\right) w h
$$

Using the bargained wage solution, we can rewrite $\Pi$ such as:

$$
\Pi=\left[\frac{\epsilon\left(\eta_{L}(1-\rho)-\rho\right)}{\left(1+\eta_{L}\right)(1-\epsilon \rho)}\right](1-\alpha) \frac{Y}{N}+\frac{\eta_{L}(1-\epsilon)}{\left(1+\eta_{L}\right)(1-\epsilon \rho)} P \bar{\omega} e \theta
$$

Using this in Equation (57), we finally obtain the labor-market tightness in steady state:

$$
\frac{\bar{\omega} \theta^{1-\psi}}{\chi}=\frac{\beta \epsilon}{(1-\epsilon \rho)(1-\beta(1-s))\left(1+\eta_{L}\right)}\left[\left(\eta_{L}(1-\rho)-\rho\right) \frac{(1-\alpha) A k^{\alpha} h}{P}-\eta_{L} \frac{1-\epsilon}{\epsilon} \bar{\omega} \theta\right]
$$

\section{B The Walrasian model}

We use the same notations as in the main text of the paper. We first provide some details about the closed-economy case, before turning to the open economy.

\section{B.1 The closed-economy model}

\section{B.1.1 Solving the model}

Household: The household's program is:

$$
\begin{aligned}
\max \mathcal{U}= & \sum_{t} \beta^{t} \log \left(C_{t}\right)-\sigma_{n} \frac{h_{t}^{1+\eta_{L}}}{1+\eta_{L}} \\
\text { s.t. } \quad & \left(1+\tau_{t}^{c}\right) C_{t}+I_{t}=\left(1-\tau_{t}^{w}\right) w_{t} h_{t}+r_{t} K_{t} \\
& K_{t+1}=(1-\delta) K_{t}+I_{t}
\end{aligned}
$$

with $\eta_{L}>0$ and $\sigma_{n}>0$.

Firms: The firm's program can be written as:

$$
\begin{aligned}
\max \Pi_{t}= & P_{H t} Y_{t}-\left(1+\tau_{t}^{f}\right) w_{t} h_{t}-r_{t} P_{t} K_{t} \\
\text { s.t. } & Y_{t}=A_{t} K_{t}^{\alpha} h_{t}^{1-\alpha}
\end{aligned}
$$

Government and good market equilibrium: The balanced budget is:

$$
G_{t}=\tau_{t}^{c} C_{t}+\left(\tau_{t}^{f}+\tau_{t}^{w}\right) w_{t} h_{t}+T_{t}
$$

In addition, the good market equilibrium is:

$$
Y_{t}=C_{t}+I_{t}+G_{t}
$$


Steady state equilibrium : The long-run equilibrium can be summarized by a system of 7 equations:

$$
\begin{array}{ll}
(C W 1) & (1-\alpha) \frac{Y}{h}=\left(1+\tau^{f}\right) w \\
(C W 2) & \delta K=I \\
(C W 3) & \frac{K}{Y}=\frac{\alpha \beta}{1-\beta(1-\delta)} \\
(C W 4) & Y=A K^{\alpha} h^{1-\alpha} \\
(C W 5) & \left(1-\tau^{w}\right) w=\sigma_{n} h^{\eta_{l}}\left(1+\tau^{c}\right) C \\
(C W 6) & Y=C+I+G \\
(C W 7) & \bar{g}=\tau^{c} \frac{C}{Y}+\left(\tau^{f}+\tau^{w}\right) \frac{w h}{Y}+\bar{t}
\end{array}
$$

\section{B.1.2 Welfare in the closed walrasian economy}

Using $(C W 1)$ and $(C W 3)$, we obtain

$$
\frac{I}{Y}=\frac{\delta \alpha \beta}{1-\beta(1-\delta)}
$$

Integrating this result in $(C W 6)$ and given $P G / Y=\bar{g}$, we deduce:

$$
\frac{C}{Y}=1-\frac{\delta \alpha \beta}{1-\beta(1-\delta)}-\bar{g}
$$

Using this last result in the labor market equilibrium (Equations $(C W 1)$ and $(C W 5)$ ), we obtain:

$$
h=\left(\frac{1-\tau^{w}}{\left(1+\tau^{f}\right)\left(1+\tau^{c}\right)} \frac{1-\alpha}{\sigma_{n} \frac{C}{Y}}\right)^{\frac{1}{1+\eta_{L}}}
$$

Given (59), this yields the long-run value for labor input:

$$
h=\left(\frac{1-\tau^{w}}{\left(1+\tau^{f}\right)\left(1+\tau^{c}\right)} \frac{1-\alpha}{\sigma_{n}\left(1-\frac{\delta \alpha \beta}{1-\beta(1-\delta)}-\bar{g}\right)}\right)^{\frac{1}{1+\eta_{L}}}
$$

Equation $(C W 4)$ leads to:

$$
Y=A^{\frac{1}{1-\alpha}}\left(\frac{\alpha \beta}{1-\beta(1-\delta)}\right)^{\frac{\alpha}{1-\alpha}} h
$$

We make use of these results when deriving the welfare effects of the tax reform in the closedeconomy walrasian case. 


\section{B.2 The Walrasian open-economy model}

\section{B.2.1 Solving the model}

The household: The intratemporal consumption choice are the same as in the labor search model, with the resulting optimal demand functions for each national variety and the associated CPI:

$$
\begin{aligned}
C_{H t} & =\xi\left[\frac{P_{H t}}{P_{t}}\right]^{-\eta} C_{t} \\
C_{F t} & =(1-\xi)\left[\frac{P_{F t}}{P_{t}}\right]^{-\eta} C_{t} \\
P_{t} & =\left[\xi P_{H t}^{1-\eta}+(1-\xi) P_{F t}^{1-\eta}\right]^{\frac{1}{1-\eta}}
\end{aligned}
$$

As for the intertemporal program, the household maximizes her intertemporal utility function (58) subject to the law of motion of capital (58) and to the budget constraint that now writes:

$$
\left(1+\tau_{t}^{c}\right) P_{t} C_{t}+P_{t} I_{t}=w_{t} h_{t}+P_{t} r_{t} K_{t}
$$

The firms: The firm's program is:

$$
\begin{aligned}
\max \Pi_{t}= & Y_{t}-\left(1+\tau_{t}^{f}\right) w_{t} h_{t}-r_{t} P_{t} K_{t} \\
\text { s.t. } & Y_{t}=A_{t} K_{t}^{\alpha} h_{t}^{1-\alpha}
\end{aligned}
$$

The household's and firm's first order conditions can be combined to be written as:

$$
\begin{aligned}
\sigma_{L} h_{t}^{\eta_{L}} C_{t} & =\frac{1-\tau_{t}^{w}}{\left(1+\tau_{t}^{c}\right)\left(1+\tau_{t}^{f}\right)} \frac{1-\alpha}{P_{t}} \frac{Y_{t}}{h_{t}} \\
\frac{1}{\left(1+\tau_{t}^{c}\right) C_{t}} & =\beta \frac{1}{\left(1+\tau_{t+1}^{c}\right) C_{t+1}}\left[1-\delta+\frac{1}{P_{t+1}} \alpha \frac{Y_{t+1}}{K_{t+1}}\right]
\end{aligned}
$$

The government and good market equilibrium: The balanced budget each period is:

$$
P_{t} G_{t}+P_{t} T_{t}=\tau_{t}^{c} P_{t} C_{t}+\left(\tau_{t}^{f}+\tau_{t}^{w}\right) w_{t} h_{t}
$$

The home good market is such that:

$$
Y_{t}=C_{H t}+I_{H t}+G_{H t}+D_{H t}^{*}
$$

with foreign demand for home varieties specified as:

$$
D_{H t}^{*}=\left(1-\xi^{*}\right)\left(P_{H t} / P_{t}^{*}\right)^{-\eta^{*}} Y_{t}^{*}
$$


The steady state equilibrium: In the long run, we assume a zero trade balance, such that:

$$
P_{H} D_{H}^{*}=P_{F}\left[C_{F}+I_{F}+G_{F}\right]
$$

With $P_{H}=1$ and the optimal demand functions (62)-(63) (extended to other motives), this can be rewritten as:

$$
D_{H}^{*}=P_{F} \frac{1-\xi}{\xi} P_{F}^{-\eta}\left(C_{H}+I_{H}+G_{H}\right)=P_{F} \frac{1-\xi}{\xi} P_{F}^{-\eta}\left(Y-D_{H}^{*}\right)
$$

from where we get:

$$
D_{H}^{*}=\frac{(1-\xi)\left(\frac{P_{F}}{P_{H}}\right)^{1-\eta}}{\xi+(1-\xi)\left(\frac{P_{F}}{P_{H}}\right)^{1-\eta}} Y
$$

The foreign demand for home varieties is specified according to Equation (66), with the foreign CPI assumed to be given by:

$$
P^{*}=\left[\xi^{*} P_{F}^{1-\eta^{*}}+\left(1-\xi^{*}\right) P_{H}^{1-\eta^{*}}\right]^{\frac{1}{1-\eta^{*}}}
$$

Using this, the zero-trade balance equilibrium condition can be rewritten as:

$$
\left(1-\xi^{*}\right)\left[\xi^{*} P_{F}^{1-\eta^{*}}+\left(1-\xi^{*}\right)\right]^{\frac{\eta^{*}}{1-\eta^{*}}} Y^{*}=\frac{1-\xi}{\xi} P_{F t}^{1-\eta}\left[C_{H t}+I_{H t}+G_{H t}\right]
$$

Using Equation (65) in (68) yields:

$$
\left(1-\xi^{*}\right)\left[\xi^{*} P_{F}^{1-\eta^{*}}+\left(1-\xi^{*}\right)\right]^{\frac{\eta^{*}}{1-\eta^{*}}} Y^{*}=\frac{(1-\xi) P_{F}^{1-\eta}}{\xi+(1-\xi) P_{F}^{1-\eta}} Y
$$

In addition, since the trade balance is zero, the resource constraint of our economy is such that production equals absorption, which yields, in terms of the home good

$$
Y=P(C+I+G)
$$


The steady-state of the open walrasian economy yields a system of 9 equations :

$$
\begin{array}{ll}
(O W 1) & (1-\alpha) \frac{Y}{h}=\left(1+\tau^{f}\right) w \\
(O W 2) & \delta K=I \\
(O W 3) & \frac{P K}{Y}=\frac{\alpha \beta}{1-\beta(1-\delta)} \\
(O W 4) & Y=A K^{\alpha} h^{1-\alpha} \\
(O W 5) & \left(1-\tau^{w}\right) w=\sigma_{n} h^{\eta_{l}}\left(1+\tau^{c}\right) P C \\
(O W 6) & Y=P(C+I+G) \\
(O W 7) & \left(1-\xi^{*}\right)\left[\xi^{*} P_{F}^{1-\eta^{*}}+\left(1-\xi^{*}\right)\right]^{\frac{\eta^{*}}{1-\eta^{*}}} Y^{*}=\frac{(1-\xi) P_{F}^{1-\eta}}{\xi+(1-\xi) P_{F}^{1-\eta}} Y \\
(O W 8) & P=\left[\xi+(1-\xi) P_{F}^{1-\eta}\right]^{\frac{1}{1-\eta}} \\
(O W 9) & \bar{g}=\tau^{c} \frac{P C}{Y}+\left(\tau^{f}+\tau^{w}\right) \frac{w h}{Y}-\bar{t}
\end{array}
$$

with the values of public spending and transfers maintained constant relative to output, ie $P G / Y=$ $\bar{g}$ and $P T / Y=\bar{t}$.

Compared with the closed economy model, we get similar equations except for the relative price terms that appears whenever the equilibrium equation involves home good versus consumption basket goods or foreign goods. The added equations $(O W 7)$ and $(O W 8)$ respectively determine the foreign relative price and the consumer price index.

\section{B.3 Fiscal devaluation in the walrasian framework: Elements of demonstration}

In this section, we provide some elements of demonstration of Propositions 1 to 4, that establish the effects of fiscal devaluation in a walrasian economy.

\section{B.3.1 Worked hours and trade balance in the long run}

Considering Equations (OW2) and (OW3), we get:

$$
\frac{P I}{Y}=\frac{\delta \alpha \beta}{1-\beta(1-\delta)} \equiv \bar{i}
$$

Using this result in Equations $(O W 5)-(O W 6)$ and given $P G / Y=\bar{g}$, we get the steady-state consumption-to-output ratio (in value):

$$
\frac{P C}{Y}=1-\bar{i}-\bar{g}
$$

With this last result in the labor market equilibrium (Equations $(O W 1)$ and $(O W 5)$ ), we obtain:

$$
h=\left(\frac{1-\tau^{w}}{\left(1+\tau^{f}\right)\left(1+\tau^{c}\right)} \frac{1-\alpha}{\sigma_{n} \frac{P C}{Y}}\right)^{\frac{1}{1+\eta_{L}}}
$$


Combined with the domestic good market equilibrium condition $(O W 6)$, using $(O W 10)$ and the law of motion of capital in steady state $(O W 2)$ gives the long-run value for labor input:

$$
h=\left(\frac{1-\tau^{w}}{\left(1+\tau^{c}\right)\left(1+\tau^{f}\right)} \frac{1-\alpha}{\sigma_{n}(1-\bar{i}-g)}\right)^{\frac{1}{1+\eta_{L}}}
$$

The production function $(O W 4)$ leads to:

$$
Y=A^{\frac{1}{1-\alpha}}\left(\frac{\alpha \beta}{1-\beta(1-\delta)} \frac{1}{P}\right)^{\frac{\alpha}{1-\alpha}} h
$$

Using this last result with $(O W 7)$ and $(O W 8)$, we deduce the trade balance equilibrium condition:

$$
\left(1-\xi^{*}\right)\left[\xi^{*} P_{F}^{1-\eta^{*}}+\left(1-\xi^{*}\right)\right]^{\frac{\eta^{*}}{1-\eta^{*}}} Y^{*}=\left[\frac{(1-\xi) P_{F}^{1-\eta}}{\xi+(1-\xi) P_{F}^{1-\eta}}\right] A^{\frac{1}{1-\alpha}}\left(\frac{\alpha \beta}{1-\beta(1-\delta)} \frac{1}{\left[\xi+(1-\xi) P_{F}^{1-\eta}\right]^{\frac{1}{1-\eta}}}\right)^{\frac{\alpha}{1-\alpha}} h
$$

\section{B.3.2 Elements of proof of Proposition 1}

Using Equations (70) and (OW1), the government's budget constraint $(O W 9)$ can be rewritten as:

$$
\bar{g}+\bar{t}=\tau^{c}(1-\bar{i}-\bar{g})+\left(\tau^{f}+\tau^{w}\right) \frac{1-\alpha}{1+\tau^{f}}
$$

Tax base comparison From the previous results, we deduce that the indirect tax base $P C / Y$ is larger than the payroll tax base $w h / Y$ as long as:

$$
\begin{gathered}
1-\bar{i}-\bar{g}>\frac{1-\alpha}{1+\tau^{f}} \\
\Leftrightarrow \quad 1+\tau^{f}>\frac{1-\alpha}{1-\bar{i}-\bar{g}} \equiv \mu
\end{gathered}
$$

which defines a lower bound on $\tau^{f}$. For a positive payroll tax rate $\left(\tau^{f}>0\right)$, which we assume, $\mu<1$ is thus a sufficient condition for the tax base enlargement condition to be fulfilled.

Fiscal devaluation and tax rates adjustments From the government's budget constraint (73), for constant values of $\tau^{w}, \bar{t}$ and $\bar{g}$, the shift from payroll taxation to indirect taxation requires that:

$$
0=(1-\bar{i}-\bar{g}) d \tau^{c}+d \tau^{f}\left[\frac{1-\alpha}{1-\tau^{w}}\right]\left[1-\frac{\tau^{f}+\tau^{w}}{1+\tau^{f}}\right]
$$

This delivers Equation (25) as giving the required change in $\tau^{c}$ as a function of $d \tau^{f}$ so as to balance the government's budget constraint (recalled here for convenience):

$$
d \tau^{c}=\frac{-\mu\left(1-\tau^{w}\right)}{\left(1+\tau^{f}\right)^{2}} d \tau^{f}
$$


Thus, $\mu\left(1-\tau^{w}\right)<1$ is a sufficient condition for having $d \tau^{c}$ lower than $d \tau^{f}$ in absolute value (ie, $\left|\frac{d \tau^{c}}{d \tau^{f}}\right|<1$ ). For positive labor tax rates $\tau^{f}>0, \tau^{w}>0$, having $\mu<1$ is a sufficient condition for the reduction in payroll taxation to require a less-than-proportional increase in the indirect tax rate, due to a tax base enlargement effect (as the condition $\mu<1$ ensures $P C / Y>w h / Y$ ).

Last, defining the tax wedge $T W$ as $T W=\frac{\left(1+\tau^{c}\right)\left(1+\tau^{f}\right)}{1-\tau^{w}}$, and differentiating it with regards to $\tau^{c}, \tau^{f}$ yields:

$$
d T W=\frac{1+\tau^{f}}{1-\tau^{w}} d \tau^{c}+\frac{1+\tau^{c}}{1-\tau^{w}} d \tau^{f}
$$

Given Equation (25) (or (B.3.2)), the above equation can be rewritten as:

$$
d T W=\frac{\frac{\left(1+\tau^{c}\right)\left(1+\tau^{f}\right)}{1-\tau^{w}}-\mu}{1+\tau^{f}} d \tau^{f}
$$

Provided that labor tax rates are positive, the condition $\mu<1$ is sufficient to ensure that fiscal devaluation reduces the overall tax distortion (ie, reduces $T W$ towards its first-rank allocation value equal to 1$)$.

\section{B.3.3 Elements of proof of Proposition 2}

Given the long-run value of output (72), the zero-trade balance condition ( $O W 7$ can be rewritten as:

$$
\left(1-\xi^{*}\right) Y^{*}=\left[\xi^{*} P_{F}^{1-\eta^{*}}+\left(1-\xi^{*}\right)\right]^{\frac{-\eta^{*}}{1-\eta^{*}}} \frac{(1-\xi) P_{F}^{1-\eta}}{\xi+(1-\xi) P_{F}^{1-\eta}} A^{\frac{1}{1-\alpha}}\left(\frac{\alpha \beta}{1-\beta(1-\delta)} \frac{1}{P}\right)^{\frac{\alpha}{1-\alpha}} h
$$

Let us also define:

$$
\Psi \equiv \frac{\left(1-\xi^{*}\right) Y^{*}}{A^{\frac{1}{1-\alpha}}\left(\frac{\alpha \beta}{1-\beta(1-\delta)}\right)^{\frac{\alpha}{1-\alpha}}}
$$

The zero-trade balance condition therefore rewrites according to:

$$
\Psi=h \underbrace{\left[\xi^{*} P_{F}^{1-\eta^{*}}+\left(1-\xi^{*}\right)\right]^{\frac{-\eta^{*}}{1-\eta^{*}}}}_{\varphi\left(P_{F}\right)} \underbrace{\frac{(1-\xi) P_{F}^{1-\eta}}{\xi+(1-\xi) P_{F}^{1-\eta}}}_{f\left(P_{F}\right)} \underbrace{\left(\xi+(1-\xi) P_{F}^{1-\eta}\right)^{\frac{\alpha}{(\eta-1)(1-\alpha)}}}_{g\left(P_{F}\right)}
$$

Equation (74) shows that the impact of the tax reform has an impact on $P_{F}$ only via the change in $h$. As a corollary, the sign of $\frac{d P_{F}}{d h}$, is sufficient to predict the effect of fiscal devaluation on the relative price of foreign goods.

The first difference of Equation (74) can be written as

$$
0=\frac{d h}{h}+\frac{d P_{F}}{P_{F}}\left[\varepsilon_{\varphi / P_{F}}+\varepsilon_{f / P_{F}}+\varepsilon_{g / P_{F}}\right]
$$


where $\varepsilon_{x / P_{F}}$ denotes the elasticity of the function $x\left(P_{F}\right)$ with respect to $P_{F}$ (for $x=\varphi, f$ or $g$ ). Precisely, from the above definitions of $f\left(P_{F}\right), g\left(P_{F}\right)$ and $\varphi\left(P_{F}\right)$, we obtain that:

$$
\begin{aligned}
\varepsilon_{f / P_{F}} \equiv f^{\prime} \frac{P_{F}}{f\left(P_{F}\right)}=\frac{(1-\eta) \xi}{\xi+(1-\xi) P_{F}^{1-\eta}}=(1-\eta)\left(1-f\left(P_{F}\right)\right)<0 \\
\varepsilon_{g / P_{F}} \equiv g^{\prime} \frac{P_{F}}{g\left(P_{F}\right)}=-\frac{\alpha}{1-\alpha} f\left(P_{F}\right)<0 \\
\varepsilon_{\varphi / P_{F}} \equiv \varphi^{\prime} \frac{P_{F}}{\varphi\left(P_{F}\right)}=-\eta^{*} \frac{\xi^{*} P_{F}^{1-\eta^{*}}}{\xi^{*} P_{F}^{1-\eta^{*}}+\left(1-\xi^{*}\right)}=-\eta^{*} f^{*}\left(P_{F}\right)<0
\end{aligned}
$$

We then deduce that:

$$
\frac{d h}{h}=\frac{d P_{F}}{P_{F}}\left[\eta^{*} f^{*}\left(P_{F}\right)+(\eta-1)\left(1-f\left(P_{F}\right)\right)+\frac{\alpha}{1-\alpha} f\left(P_{F}\right)\right]
$$

It is straightforward that $0<f\left(P_{F}\right)<1$. Besides, $\eta>1$ by assumption. Thus, the term $\left[\eta^{*} f^{*}\left(P_{F}\right)+(\eta-1)\left(1-f\left(P_{F}\right)\right)+\frac{\alpha}{1-\alpha} f\left(P_{F}\right)\right]$ is always positive. This establishes Proposition 2 .

\section{B.3.4 Elements of proof of Proposition 4}

Aggregate welfare is given by

$$
\mathcal{W}=\log C-\sigma_{n} \frac{h^{1+\eta_{L}}}{1+\eta_{L}}
$$

With aggregate consumption given by Equation (70), output by Equation (72) and using the expression for the CPI as a function of $P_{F}(O W 8)$, we can rewrite the long-run consumption level as:

$$
C=\left[1-\frac{\alpha \beta \delta}{1-\beta(1-\delta)}-\bar{g}\right] A^{\frac{1}{1-\alpha}}\left[\frac{\alpha \beta}{1-\beta(1-\delta)}\right]^{\frac{\alpha}{1-\alpha}}\left[\xi+(1-\xi) P_{F}^{1-\eta}\right]^{\frac{1}{(\eta-1)(1-\alpha)}} h
$$

This delivers the following expression for welfare:

$$
\mathcal{W}=\log \Phi+\frac{1}{(\eta-1)(1-\alpha)} \log \left[\xi+(1-\xi) P_{F}^{1-\eta}\right]+\log h-\sigma_{n} \frac{h^{1+\eta_{L}}}{1+\eta_{L}}
$$

Differentiation this expression yields:

$$
\frac{d \mathcal{W}}{d h}=\frac{1}{h}\left[1-\frac{1}{1-\alpha} f\left(P_{F}\right) \frac{d P_{F} / P_{F}}{d h / h}\right]-\sigma_{n} h^{\eta_{L}}
$$

Thus, given Equation (B.3.3), we obtain:

$$
\frac{d \mathcal{W}}{d h}=\frac{1}{h}[\underbrace{1-\frac{1}{\eta^{*} f^{*}\left(P_{F}\right)+(\eta-1)\left(1-f\left(P_{F}\right)\right)+\frac{\alpha}{1-\alpha} f\left(P_{F}\right)}}_{\Upsilon\left(P_{F}\right)}]-\sigma_{n} h^{\eta_{L}} \equiv \frac{1}{h} \Upsilon\left(P_{F}\right)-\sigma_{n} h^{\eta_{L}}
$$


Then, we have that $\frac{d \mathcal{W}}{d h}>0$ if

$$
\frac{1}{h} \Upsilon\left(P_{F}\right)>\sigma_{n} h_{L}^{\eta} \Leftrightarrow \Upsilon\left(P_{F}\right)>\sigma_{n} h^{1+\eta_{L}}
$$

Using the definition of $\Upsilon\left(P_{F}\right)$, the condition for fiscal devaluation to be welfare-improving is:

$$
\begin{gathered}
1-\frac{\frac{1}{1-\alpha} f\left(P_{F}\right)}{(\eta-1)\left(1-f\left(P_{F}\right)\right)+\frac{\alpha}{1-\alpha} f\left(P_{F}\right)}>\sigma_{n} h^{1+\eta_{L}} \\
\Leftrightarrow \quad \Upsilon\left(P_{F}\right)>\frac{\left(1-\tau^{w}\right)(1-\alpha)}{\left(1+\tau^{c}\right)\left(1+\tau^{f}\right) \frac{P C}{Y}} \\
\Leftrightarrow \quad \underbrace{\Upsilon\left(P_{F}\right)}_{\text {Price effect }} \underbrace{\frac{\left(1+\tau^{c}\right)\left(1+\tau^{f}\right)}{1-\tau^{w}}}_{\text {Tax distortion }}>\frac{1-\alpha}{1-\frac{\alpha \beta \delta}{1-\beta(1-\delta)}-\bar{g}} \equiv \mu
\end{gathered}
$$

Under Proposition 1, the overall tax distortion is reduced by fiscal devaluation. Yet, as $\Upsilon^{\prime}\left(P_{F}\right)<$ 0 and given that $P_{F}$ increases with the tax reform (Proposition 2), this proves the existence of a hump-shape welfare curve with fiscal devaluation.

\section{Calibrating the models}

\section{C.1 Calibration strategy}

France is the benchmark economy as it exemplifies a rigid labor market. Our calibration strategy can be decomposed into a two-stage process. First, we estimate a a sub-set of deep parameters so as the initial steady state is consistent with the key empirical properties of the French economy. Second, given these deep parameters values, we assess the implications of the tax reform on the main macroeconomic variables, starting from the benchmark initial calibration with the tax scheme $\left\{\tau^{f}=0.34, \tau^{c}=0.22, \tau^{w}=0.13\right\}$. We apply the same calibration strategy in both the walrasian and search economies. In what follows, we first detail the calibration of the economy featuring labor market frictions. The results of the search model are reported in Tables 1,2 and 3. We then present the calibration results in the walrasian setting.

\section{C.2 Calibration in the labor market search model}

\section{C.2.1 Step 1: Estimating the deep parameters}

We derive the model's deep parameters so as the initial steady state to be consistent with the key empirical properties of the French economy. In particular, we pay attention to match the tax base difference in consumption and payroll taxes. Not all the deep parameters are estimated though. We indeed calibrate some parameters whose value is pinned down by econometric studies. We estimate 
the values of the other parameters such that the benchmark long-run equilibrium of the model matches the following empirical targets.

The first one relates to output decomposition. Since the consumption tax applies to all consumption expenditures, the consumption aggregate includes non durables and durables, which implies $P C / Y=62 \%$ and $P I / Y=12 \%$. This low value of investment to output ratio will result in a low depreciation rate of capital $\delta$. The second set of targets deals with the tax bases considered in fiscal devaluation $(P C / Y$ versus $w N h / Y)$. We observe in the French data $\left(1+\tau^{f}\right) w N h / Y$ and $w N h / Y$, which yields $\tau^{f}$. We also observe tax revenues from indirect taxation $\tau_{c} \frac{P C}{Y}$ and employer's social security contributions $\tau^{f} \frac{w N h}{Y}$ (Landais et al. (2011)), which yields $\tau_{c}$ given $\tau^{f}$. In addition, National Accounts yields the macroeconomic ratios $P C / Y, P I / Y$ and $P G / Y$, where purchases of durable goods by households (purchases by firms) are included in $C$ (in $I$ ). One leading argument advocated by the reform's proponent relies on tax base comparison. In the data, indeed, the tax base of indirect taxation $(P C / Y=62 \%)$ is larger than that of payroll taxation $(w N h / Y=50 \%)$ : the reduction in the payroll tax rate is expected to require a less-than-proportional increase in the indirect tax rate everything else equal for a given ratio of public spending and transfers (Proposition 1). Finally, the value of transfers (relative to GDP) $\bar{t}$ is endogenously derived so as to balance the government's budget constraint, given the tax bases, tax rates and government ratio $\bar{g}$.

We also pay a particular attention to the adequacy of the open-economy dimension of the model to the data. We thus estimate the deep parameters so as the model replicates the export-to-output ratio $\left(D_{H}^{*} / Y\right.$ in terms of the mdoel's notations) as well as the import-to-output ratio $(1-\xi)$ as observed in France. Besides, we determine $\xi^{*}$ to be consistent with this calibration, altogether with the share of French GDP relative in world output $\left(Y / Y^{*}\right) \cdot{ }^{24}$ The calibration of the elasticity of substitution $\left(\eta, \eta^{*}\right)$ is open to a vast debate. Most macroeconomic models use a value between 1 and 1.5, in line with the empirical estimates obtained on aggregate data. We retain $\eta=1$ as benchmark value, similarly as in Corsetti \& Pesenti (2001) or Kollmann (2001) (among others). We calibrate the same value for $\eta^{*}$. In the sensitivity analysis, we pick up $\eta=1.5$ as in Backus et al. (1995).

Last, we want our model to be consistent with the main labor market features of the benchmark economy. The deep parameters are set so as to match the unemployment rate, the vacancy filling probability and the job finding rate observed in France. Table 1 reports the targeted features and calibrated values.

Table 2 reports the resulting estimated parameters. These values are such that the long run equilibrium from the model replicates the empirical targets in Table 1. Our choice to replicate both the labor share and the gross labor cost implies a calibrated value of $\tau^{f}=0.34$ for the payroll tax

\footnotetext{
${ }^{24}$ That is, we derive the value of $\xi^{*}$ such as: $1-\xi^{*}=\frac{D_{H}^{*}}{Y} \frac{Y}{Y^{*}}$, given the empirical targets for $\frac{D_{H}^{*}}{Y^{*}}$ and $\frac{Y}{Y^{*}}$.
} 
Table 1: Estimation Step: Calibrated parameters and empirical targets (Search model)

\begin{tabular}{|c|c|c|c|}
\hline \multicolumn{2}{|l|}{ Empirical Target } & \multirow[t]{2}{*}{ Value } & \multirow[t]{2}{*}{ Reference } \\
\hline Label & Notation & & \\
\hline \multicolumn{4}{|l|}{ Labor market features } \\
\hline Unemployment rate & $1-N$ & 0.1 & France, $1995-2008\left(^{a}\right)$ \\
\hline Working time & $h$ & 0.33 & Andolfatto (1996) \\
\hline Search effort time & $e$ & $h / 2$ & Andolfatto (1996) \\
\hline Job finding rate & $\widetilde{p}=e p$ & 0.22 & $\begin{array}{l}\text { Mean duration of unemployment } \\
14 \text { months in France, } 1995-2008\left(^{a}\right)\end{array}$ \\
\hline Unemployment benefit ratio & $\rho$ & 0.56 & France, $1995-2008\left(^{a}\right)$ \\
\hline Vacancy finding rate & $q$ & 0.7 & Krause \& Lubik (2007) \\
\hline Firms' weight in match & $\psi$ & 0.6 & Langot (1996) \\
\hline Firm's bargaining power & $\epsilon$ & 0.6 & $\epsilon=\psi$ \\
\hline \multicolumn{4}{|l|}{ Open-economy dimension } \\
\hline Exports-to-output ratio & $D_{H}^{*} / Y$ & 0.19 & France, $1995-2008\left(^{b}\right)$ \\
\hline Imports-to-output ratio & $1-\xi$ & 0.2 & France, $1995-2008\left({ }^{b}\right)$ \\
\hline Home elasticity of subst. between goods & $\eta$ & 1 & Corsetti \& Pesenti (2001) \\
\hline Foreign elasticity of subst. between goods & $\eta$ & 1 & Corsetti \& Pesenti (2001) \\
\hline Home GDP relative to foreign & $Y / Y^{*}$ & $3.48 \%$ & IMF World economic outlook, 1995-2008 \\
\hline \multicolumn{4}{|c|}{ Key ratios (relative to GDP) and fiscal policy } \\
\hline Consumption ratio & $P C / Y$ & 0.62 & France, $1995-2008\left(^{b}\right)$ \\
\hline Investment ratio & $P I / Y$ & 0.12 & France, $1995-2008\left(^{b}\right)$ \\
\hline Public spending ratio & $\bar{g} \equiv P G / Y$ & 0.25 & France, $1995-2008\left({ }^{b}\right)$ \\
\hline Employee's labor tax & $\tau^{w}$ & 0.13 & France, 1995-2008, OECD data \\
\hline Labor share & $\left(1+\tau^{f}\right) w N h / Y$ & 0.67 & France, 1995-2007, Cotis (2009) \\
\hline Gross labor cost & $w N h / Y$ & 0.5 & France, 1995-2007, Cotis (2009) \\
\hline \multicolumn{4}{|l|}{ Preferences and technology } \\
\hline TFP level & $A$ & 1 & Normalization \\
\hline Discount rate & $\beta$ & 0.99 & $\begin{array}{l}\text { Annual real interest rate of } 4 \% \text {, } \\
\text { France, } 1995-2008\left(^{a}\right)\end{array}$ \\
\hline
\end{tabular}

$\left({ }^{a}\right)$ : Authors calculations, based on OECD data.

$\left({ }^{b}\right)$ : Authors calculations, based on National Accounts provided by the statistical French administration INSEE.

rate. The value $\tau^{c}=0.22$ is obtained by combining our targeting choices reported in Table 1 with information provided by Landais et al. $(2011) .{ }^{25}$

The value for $\bar{\omega}$, altogether with the endogenous values of $P, Y$ and $V$, implies a ratio $P \bar{\omega} V / Y$ equal to 0.01 . This value lies within the range commonly used in the literature (0.005 in Chéron \& Langot (2004), 0.01 in Hairault (2002) or 0.05 in Krause \& Lubik (2007)). The quarterly destruction rate $s$ is consistent with the monthly estimate of $1.2 \%$ found by Hairault et al. (2011) using French Labor Force Survey between 1990 and 2010. The elasticity of labor supply (equal to $1 / \eta_{L}$ ) stands

\footnotetext{
${ }^{25}$ In France in 2006, fiscal revenues from indirect taxation amounted to $\tau^{c} P C=195.5$ billions of euros, while payroll taxation revenues amounted to $\tau^{f} w N h=232.5$ billions of euros. Given our calibration of $\tau^{f}, \frac{w N h}{Y}$ and $\frac{P C}{Y}$, this implicitly defines an indirect tax rate of $\tau^{c}=0.22$. This value stands in accordance with data provided by Nickell (2006) for France over 1980-2005. Also note that, if the tax base of indirect taxation is larger than that of direct payroll taxation $\left(\frac{P C}{Y}>\frac{w N h}{Y}\right)$, the order is reversed regarding the corresponding fiscal revenues, as $\frac{\tau^{c} P C / Y}{\tau^{f} w N h / Y}=0.82$
} 
Table 2: Estimation Step: The results (search model)

\begin{tabular}{|c|c|c|}
\hline \multicolumn{2}{|l|}{ Target } & Value \\
\hline Label & Notation & \\
\hline \multicolumn{3}{|l|}{ Structural parameters } \\
\hline Separation rate & $s$ & 0.024 \\
\hline Matching efficiency & $\chi$ & 0.941 \\
\hline Cost of job posting & $\bar{\omega}$ & 0.136 \\
\hline Disutility of work & $\sigma_{n}$ & 18.31 \\
\hline Disutility of search & $\sigma_{u}$ & 10.96 \\
\hline Labor supply elasticity & $1 / \eta_{L}$ & 0.56 \\
\hline Technology parameter & $\alpha$ & 0.32 \\
\hline Depreciation rate & $\delta$ & 0.006 \\
\hline Transfers to GDP ratio & $\bar{t} \equiv P T / Y$ & 0.009 \\
\hline Payroll tax rate & $\tau^{f}$ & 0.34 \\
\hline Indirect tax rate & $\tau^{c}$ & 0.22 \\
\hline \multicolumn{3}{|l|}{ Variables } \\
\hline Relative price of imports & $P_{F}$ & 24.19 \\
\hline Consumption price index & $P$ & 1.86 \\
\hline Labor market tightness & $\theta$ & 2.095 \\
\hline Number of vacancies & $V$ & 0.03 \\
\hline Capital to labor ratio & $k$ & 30.75 \\
\hline Exports volume & $D_{H}^{*}$ & 0.15 \\
\hline GDP & $Y$ & 0.80 \\
\hline Foreign demand & $Y^{*}$ & 0.91 \\
\hline Foreign CPI & $P^{*}$ & 23.67 \\
\hline
\end{tabular}

in line with the range of values commonly retained in the matching models literature (see Chéron \& Langot (2004), among others). Finally, labor market tightness $\theta$ might seem high. However, the values of $\theta$ in the literature refer to estimates that abstract from search effort. After multiplying by the search effort $e$, the French labor market tightness hovers around 0.3, which lies within the range found in the literature (0.2 in Albertini \& Fairise (2009), 0.55 in Le Barbanchon et al. (2011)).

\section{C.2.2 Step 2: Calibration}

When evaluating the effects of the tax reform, we calibrate the deep parameters to the values estimated in the Estimation step, and let the macroeconomic variables endogenously adjust to the fiscal environment. Table 3 sums up the whole set of calibrated values in the search model. Note that, given our assumption that $B=0$ in the long-run, the interest rates $\left(i^{F}\right.$ and $\left.i^{*}\right)$ do not intervene in the steady-state equilibrium. Yet, they will intervene in the transition dynamics of the tax reform. In this exercise, the foreign interest rate $i^{*}$ value (exogenous and constant) can be 
derived from Equations (8) and (24) taken in steady-state and given our assumption $B=0$. It yields $i^{*}=\frac{1}{\beta}-1$. We calibrate $\phi_{B}=0.0019$, based on the empirical estimates of Lane \& Milesi-Ferretti (2001). The capital adjustment $\operatorname{cost} \phi_{K}$ also only intervenes in the transition dynamics. We set $\phi=7$, based on Patureau (2007).

Table 3: Calibration when assessing the effects of fiscal devaluation (Search model)

\begin{tabular}{|c|c|c|c|}
\hline Parameter & Value & Parameter & Value \\
\hline \multicolumn{4}{|c|}{ Labor market } \\
\hline$s$ & 0.024 & $\epsilon$ & 0.6 \\
\hline$\chi$ & 0.941 & $\psi$ & 0.6 \\
\hline $\bar{\omega}$ & 0.13 & $\rho$ & 0.56 \\
\hline \multicolumn{4}{|c|}{ Preferences and technology } \\
\hline$\sigma_{n}$ & 18.32 & $\eta_{L}$ & 1.77 \\
\hline$\sigma_{u}$ & 10.96 & $\beta$ & 0.99 \\
\hline$\alpha$ & 0.32 & $\delta$ & 0.006 \\
\hline$A$ & 1 & $\phi_{K}$ & 7 \\
\hline \multicolumn{4}{|c|}{ Open-economy features } \\
\hline$\xi$ & 0.8 & $\eta$ & 1 \\
\hline$\xi^{*}$ & 0.993 & $\eta^{*}$ & 1 \\
\hline$Y^{*}$ & 0.91 & $\phi_{B}$ & 0.0019 \\
\hline \multicolumn{4}{|c|}{ Governmental policy } \\
\hline $\bar{g}$ & 0.25 & $\bar{t}$ & 0.09 \\
\hline
\end{tabular}

Note that, when evaluating the implications of the tax reform, we start from the initial steady state featured by $\tau^{c}=0.22, \tau^{f}=0.34$ and $\tau^{w}=0.13$.

Table 4 summarizes the status of the parameters and variables at each step, with "Step 1" referring to the Estimation stage and "Step 2" to the evaluation of fiscal devaluation. At each stage, the statement "Exo" means that the variable or parameter is exogenous, while the statement "Endo" means that it is by contrast endogenously derived.

\section{C.3 Calibration in the walrasian economy}

We undertake a similar estimation/calibration procedure as in the search model. In the absence of labor market frictions, we derive the deep parameters values so as to be consistent with the empirical ratios $(P C / Y, P I / Y$, etc. $)$ in France. The absence of job posting spending modifies the good market equilibrium condition. Accordingly, we derive the ratio of investment to output $P I / Y$ consistent with the empirical targets of $P C / Y$ and $\bar{g}$. Importantly, we specify preferences with a larger labor supply elasticity than in the search model. Precisely, we follow Prescott (2004), by adopting a log-specification on leisure. The estimation stage is reported in Table 5. 
Table 4: Exogenous vs endogenous variables in the long-run: Summary

\begin{tabular}{||c|c|c||c|c|c||}
\hline \hline Label & Step 1 & Step 2 & Label & Step 1 & Step 2 \\
\hline \hline$\alpha$ & Endo & Exo & $P I / Y$ & Exo & Endo \\
$\beta$ & Exo & Exo & $P C / Y$ & Exo & Endo \\
$s$ & Endo & Exo & $p(\theta)$ & Exo & Endo \\
$\rho$ & Exo & Exo & $q(\theta)$ & Exo & Endo \\
$\bar{\omega}$ & Endo & Exo & $Y$ & Endo & Endo \\
$\psi$ & Exo & Exo & $N$ & Exo & Endo \\
$\bar{t}$ & Endo & Exo & $h$ & Exo & Endo \\
$\bar{g}$ & Exo & Exo & $e$ & Exo & Endo \\
$A$ & Exo & Exo & $k$ & Endo & Endo \\
$\eta_{L}$ & Endo & Exo & $\theta$ & Endo & Endo \\
$\eta$ & Exo & Exo & $P_{F}$ & Endo & Endo \\
$\xi$ & Exo & Exo & $w N / Y$ & Exo & Endo \\
$\eta^{*}$ & Exo & Exo & $\tau^{w}$ & Exo & Endo \\
$\xi^{*}$ & Endo & Exo & $Y / Y^{*}$ & Exo & Endo \\
$\delta$ & Endo & Exo & $V$ & Endo & Endo \\
$\chi$ & Endo & Exo & $D_{H}^{*} / Y$ & Exo & Endo \\
$\epsilon$ & Exo & Exo & $Y^{*}$ & Endo & Exo \\
$\sigma_{n}$ & Endo & Exo & $\tau^{f}$ & Exo & Exo \\
$\sigma_{u}$ & Endo & Exo & $\tau^{c}$ & Exo & Exo \\
\hline \hline
\end{tabular}

Similarly as in the search model, when we evaluate the implications of the tax reform, we calibrate the deep parameters to the values estimated in the Estimation step, and let the macroeconomic variables endogenously adjust to the fiscal environment. Table 6 thus reports the set of calibrated parameters. As in the search model, when evaluating the implications of the tax reform, we start from the initial steady state featured by $\tau^{c}=0.22, \tau^{f}=0.34$ and $\tau^{w}=0.13$. 
Table 5: Estimation Stage in the Walrasian Open economy

\begin{tabular}{|c|c|c|c|}
\hline \multicolumn{4}{|c|}{ Empirical targets and calibrated parameter } \\
\hline Target & Value & Parameter & Value \\
\hline$h$ & 0.3 & $\xi$ & 0.8 \\
\hline$P C / Y$ & 0.62 & $\eta$ & 1 \\
\hline$P I / Y$ & 0.13 & $\eta_{L}$ & 0.429 \\
\hline$D_{H}^{*} / Y$ & 0.19 & $\eta^{*}$ & 1 \\
\hline$w h / Y$ & 0.5 & $A$ & 1 \\
\hline$\left(1+\tau^{f}\right) \frac{w h}{Y}$ & 0.67 & $\beta$ & 0.99 \\
\hline$Y / Y^{*}$ & 0.035 & $\bar{g}$ & 0.25 \\
\hline & & $\tau^{w}$ & 0.13 \\
\hline \multicolumn{4}{|c|}{ Estimated values } \\
\hline Variable & Value & Parameter & Value \\
\hline$P_{F}$ & 24.19 & $\alpha$ & 0.33 \\
\hline$P$ & 1.86 & $\delta$ & 0.006 \\
\hline$Y$ & 0.96 & $\sigma_{n}$ & 3.21 \\
\hline$P K / Y$ & 10.64 & $Y^{*}$ & 1.1 \\
\hline$D_{H}^{*}$ & 0.183 & $\xi^{*}$ & 0.993 \\
\hline \multirow[t]{3}{*}{$P^{*}$} & 23.67 & $\bar{t}$ & 0.12 \\
\hline & & $\tau^{f}$ & 0.34 \\
\hline & & $\tau^{c}$ & 0.22 \\
\hline
\end{tabular}

Table 6: Calibration when assessing the effects of fiscal devaluation (Walrasian model)

\begin{tabular}{||c|c||c|c||}
\hline \hline Parameter & Value & Parameter & Value \\
\hline \hline$\sigma_{n}$ & 3.21 & $\eta_{L}$ & 0.429 \\
$\alpha$ & 0.33 & $\delta$ & 0.006 \\
$\beta$ & 0.99 & $A$ & 1 \\
$\xi$ & 0.8 & $\eta$ & 1 \\
$\xi^{*}$ & 0.993 & $\eta^{*}$ & 1 \\
$Y^{*}$ & 1.1 & $\phi_{B}$ & 0.0019 \\
$\phi_{K}$ & 7 & $\tau^{w}$ & 0.13 \\
$\bar{g}$ & 0.25 & $\bar{t}$ & 0.12 \\
\hline \hline
\end{tabular}




\section{Documents de travail récents}

- Marc Germain: "Equilibres et effondrement dans le cadre d'un cycle naturel" [2012-12]

- Marc Hallin, Davy Paindaveine and Thomas Verdebout: "Optimal Rank-based Tests for Common Principal Components" [2012-11]

- Carlotta Balestra, Thierry Bréchet and Stéphane Lambrecht : "Property rights with biological spillovers: when Hardin meets Meade " [2012-10]

- Kirill Borissov, Thierry Bréchet, Stéphane Lambrecht : "Environmental Maintenance in a dynamic model with Heterogenous Agents" [2012-9]

- Nicolas Fleury et Fabrice Gilles : "Mobilités intergénérationnelles de capital humain et restructurations industrielles. Une évaluation pour le cas de la France, 1946-1999" [2012-8]

- Claire Naiditch, Agnes Tomini and Christian Ben Lakhdar "Remittances and incentive to migrate: An epidemic approach of migration" [2012-7]

- Nicolas Berman, Antoine Berthou and Jérôme Héricourt: "Export dynamics and sales at home" [2012-6]

- Muhammad Azmat Hayat, Etienne Farvaque: "Public Attitudes towards Central Bank Independence:Lessons From the Foundation of the ECB" [2012-5]

- Amandine Ghintran, Enrique Gonzales-Arangüena and Conrado Manuel : "A Probabilistic position value" [2011-4]

- Sophie Dabo-Niang, Anne-Françoise Yao : "Kernel spatial density estimation in infinite dimension" [2011-3]

- Xavier Chojnicki, Lionel Ragot: "Impacts of Immigration on Aging Welfare-State - An Applied General Equilibrium Model for France" [2011-2]

- Kirill Borissov, Stephane Lambrecht: "Education, Wage Inequality and Growth“ [2011-1] 